\title{
Las consecuencias de tener poco en el proceso civil chileno y sus posibles soluciones
}

The consequences of having little in the chilean civil process and its possible solutions

Nicolás Ignacio Ariel Carrasco Delgado ${ }^{1 \otimes}$

Fecha correspondencia:

Recibido: 15 de diciembre de 2020.

Revisión: 26 de abril de 2021.

Aceptado: 3 de mayo de 2021.

Forma de citar:

Carrasco, Nicolás Ignacio Ariel.

(2021). "Las consecuencias de

tener poco en el proceso civil

chileno y sus posibles soluciones".

". En: Revista CES Derecho. Vol.

12, №. 1, enero a junio de 2021,

176-207.

\section{Open access}

Términos de uso

Licencia creative commons

Etica de publicaciones

Revisión por pares

Gestión por Open Journal System

DOl: https://dx.doi.org/10.21615/

cesder.12.1.10

ISSN: 2145-7719

Sobre los autores:

1. Licenciado en Ciencias Jurídicas

y Sociales de la Universidad de

Chile. Magíster en Derecho, con

mención en Derecho Económico,

Universidad de Chile. Diplomado

en Regulación y Economía,

Facultad de Economía y Negocios de la Universidad de Chile. Doctor en Derecho, Gobierno, y Políticas

Públicas de la Universidad

Autónoma de Madrid. Profesor

Asistente de Derecho Procesal,

Universidad de Chile.

\section{Resumen}

Los problemas distributivos tienen un tratamiento extenso en diversos campos del conocimiento. Sin embargo, el Derecho Procesal Civil en Chile ha quedado ajeno a tales problemáticas. Lo anterior, a pesar que las consecuencias de tener poco (dinero) son relevantes y cruzan todo el proceso. La escasa bibliografía sobre el tema se concentra en las dificultades de acceso a la justicia, pero no a las consecuencias que las desigualdades tienen en el ámbito probatorio, en la ejecución, y en la producción de precedentes. Este artículo busca identificar esos problemas y dar algunas luces de cómo en general deben ser solucionados.

Palabras claves: Derecho procesal civil, pobreza, análisis económico del derecho, eficiencia, distribución.

\section{Abstract}

Distribution problems have an extensive treatment in different fields of knowledge. Civil Procedural Law in Chile has remained oblivious to such problems. The above, despite the fact that the consequences of having little (money) are relevant and cross the whole trial. The limited bibliography on the subject focuses on the difficulties to access to justice, but not on the consequences that the inequalities have on probationary period, in compliance with judgement, and on the production of precedents. This article seeks to identify these problems and give some light on how they should generally be solved.

Keywords: civil procedural law, poverty, law and economics, efficiency, distribution.

\section{Introducción al problema distributivo en el proceso civil}

La historia del proceso civil moderno, posterior a la dictación de los Códigos decimonónicos, está imbuido de una tradición liberal y escolástica. En su primera vertiente, se reconocen ciertos valores de libertad ensalzados por la Revolución Francesa, lo que se refleja en la subsistencia de un principio dispositivo amplio, así como en el entendimiento del proceso como mecanismo de resolución de conflictos (Colombo, 1968, p. 8; Santos, 2000, p. 19). Por su parte, la tradición escolástica persistió en la forma de los procedimientos, ya que el orden consecutivo escrito, falto de inmediación y desconcentrado que 
surgió de muchos de los Códigos dictados durante el siglo XIX y comienzos del siglo XX (entre ellos, el Código de Procedimiento Civil chileno), se basada en el procedimiento usado al interior de la Iglesia Católica que fue reconocido por las legislaciones castellanas e indianas.

La tradición liberal empezó a recibir críticas en Alemania a fines del siglo XIX. Se cuestionaba que el proceso quedara a disposición de las partes, dado que en el proceso civil igualmente existían intereses públicos comprometidos. Dentro de los cuales, particular importancia adquiría el principio de igualdad. En efecto, se señalaba que el proceso no podía ser un instrumento que replicara las desigualdades socio-económicos existentes entre las partes fuera del ámbito procesal. Esta invocación publicista del procedimiento generó cambios en la manera de ordenar el proceso que terminaron creando una nueva manera de estructurar sus etapas, despojándose los procedimientos civiles de su tradición escolástica, permitiendo un acceso más directo, público y transparente de los justiciables al juez, lo que se concretizó por medio del proceso por audiencias y con el fortalecimiento de la oralidad y concentración (Sturner, 2007, p. 441). Lo anterior, aún no sucede en Chile con el proceso civil, pero existe la esperanza que acaezca con el largo transitar que ha tenido el Proyecto de Nuevo Código Procesal Civil'1.

Con todo, es interesante destacar que la tradición publicista no logró su primer objetivo, referido a introducir espacios de igualdad en un procedimiento que potencialmente enfrentaba a partes desiguales. Se pensó que el juez podía suplir tal desigualdad. Asimismo, se crearon instrumentos legales que implicaban inversión pública (por ejemplo, creación de organismos de asistencia gratuita). Sin embargo, es posible constatar que, transcurrido bastante tiempo de intentos y reformas en ese sentido en el derecho comparado, la situación no ha cambiado. El proceso civil no se hace cargo de las desigualdades extra-procesales dentro del proceso. Idéntica constatación aplica a las reformas parciales que se han realizado a los procedimientos civiles en Chile, donde enfocaremos el presente trabajo².

Esa realidad parece controvertida por algunos autores que entienden que, ciertos instrumentos procesales que examinaremos y que se contemplan en nuestra normativa, constituyen mecanismo distributivo efectivos a favor de quienes carecen de recursos. De hecho, en un libro publicado el año 2013 sobre la igualdad y el Derecho (Muñoz, 20013), en su capítulo sobre Derecho Procesal, la conclusión parece bastante alentadora, al señalarse que: "El derecho chileno contemporáneo contempla plenamente instituciones igualadoras como la presunción de inocencia en el proceso penal; una concepción activa de los jueces civiles y laborales; unas especiales formas de legitimación activa que potencian la figura del demandante en casos de consumo o de tutela de los derechos fundamentales de los trabajadores; normas sobre facilitación de la prueba en materia de procedimientos de tutela de derechos fundamentales de los trabajadores que, de una manera aún más fuerte, probablemente se introducirán en el nuevo Código Procesal Civil; presunciones de culpabilidad de daño ambiental en caso de incumplimiento de normativas ambientales, financiamiento de los informes periciales en los juicios por daño ambiental, etcétera" (Bordalí, 2013, p. 230).

1. Un proceso que comenzó el año 2005 por medio de la constitución del Foro Procesal Civil, donde se sentaron las bases generales y principios del nuevo sistema y la discusión y generación del contenido del proyecto de Código Procesal Civil. Los documentos fundamentales para el trabajo de ese Foro fueron aquellos elaborados por la Facultad de Derecho de la Universidad de Chile ("Propuesta de Bases para redactar un Nuevo Código Procesal Civil para la República de Chile"), y el preparado por la Facultad de Derecho de la Pontificia Universidad Católica de Chile ("Bases Generales para una Reforma Procesal Civil") y que culminó con el mensaje presidencial 398-357, de 18 de mayo de 2009, que fue posteriormente retirado de la tramitación parlamentaria. Posteriormente, se dio origen a una Comisión Intraministerial para la Reforma Procesal Civil del año 2010 (conformada por los profesores Cristián Maturana José Pedro Silva, y Raúl Tavolari), a la que se sumó un Consejo Asesor. Como consecuencia, se presentó al Congreso un nuevo Proyecto de Código Procesal Civil por medio del mensaje presidencial 432-359, de 12 de marzo de 2012, que se encuentra en actual tramitación en segundo trámite constitucional ante el Senado y que ha tenido una tramitación lenta y trabajosa, con muchos periodos de inactividad y nulo avance.

2. Entenderemos por procedimientos civiles un concepto amplio que abarca todo procedimiento no penal. 
Compartimos con esa visión el que algunos avances se han logrado respecto de la situación existente a 1903, cuando se dictó el Código de Procedimiento Civil (en lo sucesivo C.P.C). Parte de esos avances serán tratados en este trabajo, pero quedará en evidencia que las reformas que lo han establecido no han formado parte de un ideario común con vistas a entregar una regulación que permita un tratamiento procesal que aminore las desventajas que generan las carencias de "quienes tienen poco", y que reduzcan las externalidades asociadas a las ventajas de quienes no se encuentran en tal posición. Al respecto, es esencial darse cuenta de que no sirve el reconocimiento programático o formulado en base a una declaración de principios. Lo relevante es que existan instrumentos que permitan que el proceso sea un mecanismo distributivo cuando pueda cumplir esa función y, siempre, que sea necesario y eficiente hacerlo.

Esas exigencias de efectividad y de justificación distributiva no han sido abordadas de manera sistemática por la doctrina. Por efectividad de las normas distributivas, entenderemos aquella situación que se da cuando se cumplen los objetivos de las normas procesales que tienen por finalidad atenuar, morigerar o eliminar las desventajas distributivas a que se ven enfrentados "quienes tienen poco". Por tanto, la valoración de la efectividad requiere de un trabajo empírico que demuestre que las finalidades buscadas por las normas efectivamente se cumplen (Carrasco, 2019). Por su parte, la justificación distributiva surge cuando una norma procesal incentiva o favorece un detrimento de aquellas "personas que tienen poco", restringiendo o dificultando su acceso a la justicia, sus capacidades para formular alegaciones o realizar actividades probatorias, o bien, porque incrementa las diferencias de recursos que esas personas tienen con quienes no están afectos a restricciones presupuestarias para litigar.

\section{Una visión en serio de tener poco}

Ideas preliminares sobre las maneas de examinar las consecuencias de tener poco Para afrontar la temática de "aquellos que tienen poco" en el proceso, debemos introducir algunas ideas sobre la pobreza y sus consecuencias en el proceso, aunque es evidente que esto se hace a modo introductorio, siendo insuficiente para examinar tal materia en profundidad. Sin embargo, se busca generar un marco teórico que habilite un desarrollo posterior sobre las consecuencias distributivas que la pobreza genera en el proceso civil.

El tratamiento de la pobreza ha sido estudiado desde múltiples perspectivas. En lo que interesa en este trabajo y, con el riesgo de ser extremadamente simplista, podemos mencionar cuatro. La primera refiere al estudio de las circunstancias sociológicas, económicas, o políticas que producen un ambiente de pobreza (Lewis, 1966; Harvey y Reed, 1996. En sentido crítico: Howe, 1998). La segunda perspectiva de estudio se centra en las consecuencias que la pobreza produce en múltiples variables como niveles de educación, salubridad, condiciones de vida, acceso a tecnología, participación política, etc (Hernando, 2016; para una definición económica-biológica de bienes de primera necesidad: Scitovsky, 1968, pp. 121-122). Una tercera perspectiva se centra en las capacidades y no en los recursos económicos, sobre la base de que diferentes personas pueden tener distintas oportunidades de convertir ingresos en características de buena vida, de modo que la relación entre recursos y pobreza es variable y dependiente de las características de las personas y del ambiente en que se desenvuelve (Sen, 2013, pp. 283-298). Esta perspectiva de la pobreza ha sido conceptualizada como pobreza secundaria, como opuesta a la pobreza primaria que 
surgiría de la falta de recursos económicos (Rowntree, 2000). Finalmente, la cuarta perspectiva, tiene un componente más psicológico, y se focaliza en la mentalidad que se crea a causa de la escasez de recursos y la forma en que esa mentalidad reintroduce los problemas asociados a la pobreza en diversas instancias de decisión de la "persona que tiene poco".

Utilizaremos las herramientas conceptuales de la cuarta perspectiva. Al respecto, hablaremos de "personas que tienen poco" para reflejar una serie de consecuencias que se derivan de la escasez de recursos económicos en el proceso. Considero que el análisis centrado en el "sujeto que tiene poco" es más adecuado de ser estudiado en base a la cuarta perspectiva, ya que al enfocar la cuestión en el sujeto que carece de recursos y sus decisiones en un procedimiento, deja de tener trascendencia las razones que originaron su pobreza (primera perspectiva), la que ahondaría en los motivos por los cuales la persona tiene poco, lo que nos ubica en momentos anteriores a aquellos referidos en este artículo. Asimismo, si bien la segunda perspectiva podría servir al Derecho Procesal para entregar índices cuantitativos sobre la manera que se relaciona la variable pobreza y el proceso civil (como, tasa de litigación de las personas que tienen poco versus aquellas que tienen una mejor condición económica, o, proporción del gasto asociado al litigio civil en el total de los desembolsos de las personas que tienen poco, etc.), esa perspectiva generaliza, en una variable o un número, aquello que queremos examinar de manera más concreta. La tercera perspectiva, exige un estudio más comprensivo del fenómeno de la pobreza que atiende a las capacidades habilitantes para el desarrollo de la vida, de modo que su debido tratamiento excede con mucho el objeto de este artículo.

Pues bien, para estos efectos y de acuerdo a la cuarta perspectiva, se entenderá que el proceso civil se configura como un bien cuyo acceso y consumo requiere de una serie de gastos que es necesario desembolsar para disfrutar de sus beneficios. Dado que esos gastos se van devengando en diferentes momentos o etapas del procedimiento, conduce a que las decisiones sean diversas de acuerdo al evento que origina el gasto respectivo. Simplificaremos esas etapas de acuerdo a la estructura habitual que posee un procedimiento civil donde existe un rol preponderante de las partes, en: inicio del procedimiento; etapa de prueba; etapa de ejecución, y generación de precedentes. Se ha excluido la etapa de sentencia porque el rol fundamental compete al juez, sujeto que es excluido de análisis.

Pues bien, la cuarta perspectiva que se examina establece la hipótesis que las "personas que tienen poco" toman decisiones sobre los gastos que deben afrontar de manera que, muy probablemente, reintroducirán su situación de escasez. Como consecuencia, la carencia de recursos hace que cada gasto sea más apremiante y que la carencia respectiva capture mayormente la atención de esas personas. Por ejemplo, una persona en situación de inanición se focaliza principalmente en comida. El problema es que la atención en aquello que se carece, lidera una negligencia respecto de otras preocupaciones que, también, son objetivamente relevantes. Este fenómeno se llama "negligencia atencional" y explica las razones por las cuales las personas de bajos ingresos toman préstamos a corto plazo y con altos intereses, con miras a resolver necesidades acuciantes, pero comprometiendo el pago de gastos futuros. Este efecto se puede explicar porque el préstamo puede ser entendido como la posibilidad evitar el sufrimiento en el corto plazo de una gran pérdida (no satisfacer las necesidades apremiantes y sin capacidad de solventar sin el préstamo), dando una pequeña esperanza de que en el futuro pueda evitarse nuevamente esa gran pérdida (Kahneman, 2017, pp. 415-416). 
Un efecto necesario de lo anterior es que las personas con escasos recursos van acumulando mayor cantidad de deuda con cargo al presupuesto futuro, generando que muchos otros problemas (distintos de las necesidades inmediatas de dinero) queden relegadas en importancia y, por tanto, desatendidas.

En ese contexto, los gastos del proceso civil aparecen como un desembolso no apremiante y, por tanto, desatendido. El costo que implica litigar no genera una carga cognitiva idéntica que el costo de proveerse alimentos. De hecho, en el modelo típico de litigación civil, que examinaremos en la ecuación [1], el monto que recibirá el demandante en caso de obtener un resultado favorable en el proceso se visualiza como un potencial ingreso futuro y, por tanto, como un bien que solo generará gastos con una más o menos incierta probabilidad de recuperación. En otras palabras, se trata de un bien que naturalmente generará "negligencia atencional". Lo que se agrava porque el demandante visualiza el proceso dentro de un marco de ganancias, que conduce a que aversión al riesgo, es decir a un cierto desincentivo a demandar (Richlinski, 1996, pp. 122-127).

Esa despreocupación solo tiende a afectar a la "persona que posee poco" y no a aquel que posee mucho. Esto tiene consecuencias distributivas en el proceso porque traerá consigo desventajas o desincentivos para el primero y ventajas o incentivos para el segundo. El proceso civil, sostengo, debe ser capaz de ser consciente de esos aspectos distributivos para consagrar reglas que limiten los efectos perniciosos que afectan al "sujeto que posee menos" dada la "negligencia atencional" que probablemente le afectará.

\section{Un marco teórico para examinar las consecuencias de tener poco en el proceso civil}

Por las razones señaladas las "personas que tienen poco" son usuarios o jugadores ocasionales en la litigación civil (en lo sucesivo "JO"). Es decir, concurren escasamente a la administración de justicia. De hecho, en el marco de la cuarta perspectiva, las "personas que tienen poco" concurrirán a la justicia civil cuando se trate de una necesidad apremiante. Incluso, en ese caso, dependiendo de factores tales como costos subsecuentes, demora en la decisión, y esclarecimiento de las probabilidades de ganar o perder, puede que surja una "negligencia atencional" que era inexistente al momento de dar inicio al proceso.

Tal marco de análisis no aplica a quienes poseen un nivel de bienestar mayor. Más aún aquellas personas por diversas razones, entre las que se encuentran su mayor cantidad económica, utilizan los tribunales de manera más recurrente, corresponderá a jugadores repetidos (en lo sucesivo "JR").

A lo largo de este trabajo iremos examinando ciertas diferencias entre los JO y los JR. Por ahora, interesa enmarcar el objeto de estudio. Para ello podemos recurrir al siguiente cuadro que indica las posibilidades de conflicto entre esas clases de litigantes.

Cuadro 1. Clasificación de configuración de enfrentamientos entre JO y JR.

\begin{tabular}{cc}
\hline JO vs JO & JR vs JO \\
\hline JO vs JO & JR vs JR \\
\hline
\end{tabular}


Nos enfocaremos en las consecuencias distributivas que surgen de un conflicto entre un JR y un JO, cuando este último es una "persona que tiene poco". Solamente en ese caso se hace posible que el JR pueda explotar en su beneficio las ventajas estratégicas que su calidad le otorga en la justicia civil. Tal escenario extiende las consecuencias distributivas en contra de "quien tiene poco" más allá de las desventajas que esa calidad supone para esas personas. Por tanto, el cuadro 1 puede modificarse para incluir el sub-conjunto de casos que nos interesa en este trabajo (sub-cuadro oscuros en el cuadro 2).

Cuadro 2. Clasificación de configuración de enfrentamientos entre JO y JR que es materia de análisis en este trabajo.

\begin{tabular}{cc}
\hline \multirow{2}{*}{ JO vs JO } & JR vs JO \\
& $\begin{array}{c}\text { JR vs JO (que } \\
\text { tienen poco) }\end{array}$ \\
\hline JO vs JO & JR vs JR \\
\hline
\end{tabular}

Elaboración propia

El cuadro oscuro da cuenta de un subconjunto de supuestos de enfrentamientos entre JR y JO. Esta precisión es necesaria para delimitar el ámbito de estudio y sirve para clarificar algunas cuestiones relevantes. En primer lugar, no todos los JO son "personas que tienen poco". De hecho, no existe una relación necesaria entre tener dinero y una capacidad económica importante y participar habitualmente de litigios civiles. Posiblemente esa capacidad económica no va a ser un desincentivo a litigar en todas las circunstancias y, además, en ningún caso es un factor que incida causalmente en una mayor propensión al litigio. En segundo lugar, podría ocurrir que "alguien que tenga poco" sea un JR, como ocurre con el infractor habitual quien se ve compelido a participar en procesos judiciales de manera habitual. Esa reincidencia, además, trae algunas consecuencias respecto de la decisión racional de delinquir como, por ejemplo, adquirir mayor experiencia e información acerca de las probabilidades de detección y sanción (Donario, 2008, p. 14). Cabe precisar que este reincidente infractor está más pensado para el caso de delitos penales que para conflictos civiles que es nuestro foco de atención. Finalmente, en tercer lugar, las calidades de JO y JR no están asociadas a una posición determinada en el proceso, es decir, como demandante o demandado. Tanto los JO como los JR pueden ser sujetos pasivos o sujetos activos. En lo sucesivo se harán algunas precisiones sobre esas calidades, ya que en este trabajo examinándose supuestos en los cuales los JO tienen el carácter de demandantes (como, por ejemplo, cuando se estudie las consecuencias distributivas que perjudican a "quien tiene poco" respecto de la decisión de iniciar una acción).

Es importante aclarar que se busca eliminar las ventajas que posee el JR. Ello sería imposible y un ejercicio inútil. No es plausible que las normas procesales o el juez puedan hacer desaparecer las utilidades de recurrir habitualmente a procesos civiles. Esas utilidades muchas veces se originan inconscientemente por los mismos jueces en su trato y relación informal con esos litigantes. Asimismo, la permanencia de la ley genera una posición en contra del cambio que produce ventajas para quienes favorecen mantener el status quo (muy probablemente los JR); incluso, en el caso que ellos no sean los beneficiados con las normas, tendrán mayores posibilidades de ejercer lobby para cambiarlas (De Figuereido y De Figuereido, 2002). 


\section{Problemas de tener poco en el proceso civil}

\section{Al momento del inicio de la acción}

La literatura económica ha estudiado cuando un litigante potencial decidirá ir a la justicia.

Donde:

P : probabilidad de que el demandante gane el caso;

W : renta bruta inicial del demandante;

$\mathrm{Cl}$ : costos monetarios del juicio para el demandante (abogados, tiempo, etc.).

M : cantidad monetaria reclamada (cuantía del juicio).

$P^{*} \quad$ : nivel crítico de probabilidad de acceso a la justicia.

En este sentido, siguiendo a un autor nacional (Mery, 2006, pp. 4-5), tenemos que el esquema básico supone que un potencial litigante neutral al riesgo ${ }^{3}$, decidirá acudir a la justicia sí y sólo sí:

$$
P(W-M-C l+M)+(1-p)(W-M-C l) \geq W-M \quad[1]^{4}
$$

La parte derecha de dicha fórmula $[P(W-M-C l+M)+(1-p)(W-M-C l)]$, corresponde al valor probable que el demandante obtendrá de ir a juicio. Dicha parte de la ecuación está conformada por dos sub-partes, la primera de ellas $[P(W-M-C l+M)]$, corresponde al valor probable que el demandante obtendrá de ganar el juicio. La probabilidad de obtener un resultado favorable $(P)$, se multiplica al resultado que surge de las operaciones que consideran la riqueza inicial del demandante (W), menos el valor que ha perdido como consecuencia de la actividad del demandado (-M), menos los costos del proceso $(-C)$, y más la recuperación de lo reclamado (M). La segunda sub-parte del lado derecho de la ecuación $[(1-p)(W-M-C l)]$, corresponde al valor probable que el demandante obtendrá de perder el juicio, donde la probabilidad de un resultado negativo para el actor (1-p) se multiplica al resultado de las operaciones que consideran la riqueza inicial del demandante (W), menos el valor que ha perdido como consecuencia de la actividad del demandado (-M), menos los costos del proceso $(-\mathrm{C})$.

Por el otro lado, la parte izquierda de la ecuación (W - M), representa la decisión del sujeto de no ir a juicio, y comprende la operación de sustracción de la riqueza inicial del demandante $(W)$, menos el valor que él ha perdido como consecuencia de la actividad del demandado (-M).

Ahora bien, según Mery -siguiendo a Shavell- de acuerdo a la expresión anterior, el individuo neutral al riesgo decidirá acudir a la justicia única y exclusivamente si la ganancia marginal neta de acudir a la justicia es positiva. 0 sea, el demandante obtendrá al final del proceso un valor pecuniario positivo, si:

3. También es posible una litigación del adverso al riesgo y del propenso al riesgo. En (Mery, 2006, pp. 5-7), se señala que si denotamos la primera de riesgo como $[r(w)]$, en el caso del neutral al riesgo la ecuación es: $[r(w)=0]$ : (1.2). Si el factor de riesgo del adverso al riesgo es $[r(w)>0]$, entonces, ese facto tendrá valor positivo, y deberá sumar la parte de la ecuación que representa la alternativa del sujeto de no ir a justicio. Por lo mismo, habrá menos juicios que en el supuesto del neutral al riesgo, según: $+r(w)(1.3)$. Por su parte, el factor de riesgo del propenso al riesgo tiene valor negativo $[r(w)<0]$, y se deberá restar a la parte de la ecuación que representa la alternativa del sujeto de no ir a juicio. Por lo tanto, habrán más juicios que en los escenarios (1) y (2) [3>2>1], según: (1.4)

4. La resolución de esa ecuación es:

$$
\begin{gathered}
(W-M-C l+M)+(1-p)(W-M-C l) \geq W-M \\
P(W-M-C l+M)+(1-p)(W-M-C l) \geq W-M \\
P(W-C l)+(1-p)(W-M-C l) \geq W-M \\
P W-P G l+[(W-M-C l)(-p W+P M+P C l) \geq W-M \\
(P M) \geq C l \\
P \geq \frac{C l}{M}
\end{gathered}
$$




$$
P \geq \frac{C l}{M}
$$

Con todo, a pesar que como consecuencia de la ecuación [2] exista una ganancia marginal neta positiva de acudir a la justicia (o sea, el juicio genera para el demandante más beneficios que costos), puede ocurrir que esa ganancia marginal neta positiva (por ejemplo \$10), no supere lo que Mery, denomina el "nivel crítico de probabilidad para acceder a la justicia" $\left(P^{*}\right)$, esto es, el nivel monetario que cada litigante considera como valor mínimo para acudir a la justicia (por ejemplo, una persona puede decidir que no litigará si el valor probable a obtener en juicio es menor a \$ 100). En otras palabras, si no se supera ese límite el demandante no litigará.

Por el contrario, si el nivel crítico de probabilidad de acceso a la justicia es igual o mayor a la ganancia positiva marginal neta de acudir a la justicia, entonces, se demandará:

$$
p \geq \frac{C l}{M}=\mathrm{p}^{*}
$$

Como consecuencia de lo señalado, el nivel de inversión de una parte en juicio depende, según el análisis económico referido, de una serie de factores expresados en la ecuación [1] y que corresponden a la probabilidad de obtener un resultado favorable, a la renta bruta inicial que pueda poseer el demandante, los costos monetarios del juicio para el actor, la cantidad reclamada y el nivel crítico de probabilidad de acceder a la justicia.

En este sentido, resulta posible obtener algunas conclusiones. Si los costos monetarios del juicio para el demandante son mayores que la cantidad reclamada $(\mathrm{Cl}>\mathrm{M})$, entonces, nunca demandará, siendo condición necesaria para que el individuo decida acudir a la justicia que $(\mathrm{Cl}<\mathrm{M})$ (Mery, 2006, p. 5). Esto genera un primer problema distributivo porque significa que el acceso a la justicia, se encuentra en este escenario, condicionado por una cierta capacidad económica.

Se podría señalar que esa conclusión no sería efectiva con el privilegio de pobreza que, más allá de su denominación peyorativa respecto de las personas pobres como beneficiarios de sus servicios ${ }^{5}$, permite una asistencia judicial a aquellas personas que carecen de recursos para litigar. Se ha definido esa institución como "el conjunto de normas legales destinadas a facilitar a las personas pobres o de escasos recursos el ejercicio de sus derechos ante los tribunales de justicia" (Casarino, 2006, p. 187), la que tiene en Chile fundamento constitucional (artículo $19 \mathrm{~N}^{\circ} 3$ de la Constitución Política de la República), y en materia civil, laboral, y de familia es provisto por las Corporaciones de Asistencia Judicial (artículo 2 Ley 17.995), y en materia penal por las Defensorías Penales ${ }^{6}$. En cualquiera de esos sistemas, la defensa y asesoría jurídica es gratuita ${ }^{7}$. En materia civil, los beneficiarios de esa asesoría se determinarán previa calificación socioeconómica ${ }^{8}$, cuando sean derivados por resolución del juez, o, en ciertos casos, sin necesidad de esa calificación, cuando concurran ciertos criterios de vulnerabilidad (personas con discapacidad, víctimas de delitos violentos, etc.). En materia penal los factores económicos son fundamentales, pero también se incluyen como beneficiarios aquellos inscritos en el Registro Social de Hogares, que

5. Existe un proyecto de ley para cambiar la redacción de nuestra legislación desde conceptos estigmatizadores como "pobre" a "beneficiario de asistencia jurídica gratuita". Así consta en el Boletín $N^{\circ} 10.135-07$, proyecto de ley, que modifica diversos cursos legales en lo relativo a esas denominaciones. 6. Institución creada por la Ley 19.718, en el contexto de la Reforma Procesal Penal, cuya finalidad es "proporcional defensa penal a los imputados o acusados por un crimen, simple delito o falta que sea competencia de un juzgado de garantía o de un tribunal de juicio oral en lo penal y de las respectivas Cortes, en su caso, y que carezcan de abogado" (artículo 2). Estos servicios son prestados por abogados que forman parte de la misma Defensoría Penal Pública y que funcionan en las Defensorías Locales, que corresponden a las unidades operativas de esa institución (artículo 23 de la Ley 19.718), así como por abogados privados que son contratados en licitaciones de defensa penal (artículos 42 y siguientes de la Ley 19.718).

7. En materia penal es posible que se cobren por los servicios de defensoría penal, de manera total o parcial, si la persona dispone de recursos para financiarla privadamente (artículo 36 de la Ley 19.718), posibilidad no contemplada para la defensa que pueden prestar las Corporaciones de Asistencia Judicial.

8. Tendrá este derecho a asesoría gratuita cuando presenten una capacidad de pago per cápita inferior o igual a 3 UF mensual. 
es un instrumento que permite incluir personas en situación de vulnerabilidad. De esta manera, considerando estos últimos factores, podemos concluir que el concepto de beneficiado da cuenta una idea de pobreza e incapacidad de pago no solamente monetaria, sino que comprende supuestos de pobreza secundaria.

Dados los beneficios que esta asesoría produce para los beneficiarios del privilegio de pobreza, entonces, se consagra un sistema de subsidio institucional a la litigación de esas personas, de modo que el desembolso de los costos del juicio no constituya una barrera de entrada a la litigación. Esta liberación de pagos comprende los honorarios de los auxiliares de la administración de justicia.

Cabe observar que en la redacción del CPC subyace una solución liberal al problema de la litigación de "aquellos que carecen de recursos", porque el andamiaje institucional que se indicó con miras a entregar asesoría a aquellas personas no fue la solución que se dio originalmente. En efecto, el Estado no desembolsaba recursos para hacerse cargo de esa cuestión distributiva, encargándose por la Ley 4.409, tal labor al Colegio de Abogados (Colegio de Abogados, 2008, pp. 1-3), y a los abogados del turno, sistema privado de provisión de asesoría jurídica, que se origina por una designación de los Jueces de Letras para que los abogados, mensualmente y por turnos, defiendan gratuitamente las causas de las personas que hubieran obtenido el privilegio referido (artículo 595 del Código Orgánico de Tribunales), sistema que aún subsiste?.

Ahora bien, volviendo a la fórmula [1], Mery agrega que si $\mathrm{M}>\mathrm{Cl}$, entonces, $\mathrm{W}>\mathrm{Cl}$, toda vez que, si $W \geq M$, resulta razonable pensar que un individuo nunca perderá en el proceso-, más renta de la que inicialmente tenía. De ello se sigue que: (i) Si el demandante gana el juicio su renta será siempre positiva $(\mathrm{W}-\mathrm{Cl}$ ), y (ii) Si pierde el juicio, su renta podrá ser negativa o positiva, dependiendo de los valores involucrados $(\mathrm{W}-\mathrm{M}-\mathrm{Cl})$.

La conclusión (ii) anterior, puede originar que siendo eficiente que exista un litigio $(\mathrm{M}>\mathrm{Cl}$ ), el mismo no llegue a iniciarse, toda vez que, la posibilidad del demandante de ser pernicioso en el resultado del juicio determine una renta negativa futura, que lo desincentive a litigar (Mery, 2006, p. 5). Así, el litigante será reticente a litigar, a pesar de tener una capacidad económica suficiente para solventar los costos del proceso, siempre que pierda. Como este último suceso es futuro, entonces, lo que determina este supuesto de no-litigación es la probabilidad de obtener un resultado desfavorable.

Un aspecto importante de referir es que, de existir escasa probabilidad de ganar un juicio, la valoración del potencial litigante (que lo lleva a no iniciar el proceso) es consistente con el interés social de que no se inicie el proceso. El interés público, según vimos en la fórmula [1], depende de que exista una probabilidad de que el actor obtenga un resultado favorable en el proceso, de otro modo, no se justifica socialmente que se incoe una acción. Esto permite concluir que la carencia de recursos de un litigante como consecuencia de obtener un resultado negativo en el juicio no es un problema distributivo que deba preocupar normativamente, ya que los mecanismos que tratan de afrontar tales problemáticas, no están hechos para subsidiar aquellas acciones que tienen escasas probabilidades de ganar.

9. A pesar de lo cual el Tribunal Constitucional ha resuelto (por ejemplo, en STC 755-2017-INA), la inconstitucionalidad de la expresión "gratuitamente" que se contiene en el artículo 595 del Código Orgánico de Tribunales, por cuanto infringe la garantía de igualdad ante la ley y de cargas públicas y la garantía de libertad de trabajo y libertad de empresa, en (Humeres, 2009). 
En esa línea, el privilegio de pobreza ayuda a evitar una divergencia en el interés público y privado asociado al inicio de un proceso, dado que se denegará ese privilegio cuando las probabilidades de obtener un resultado favorable son escasas. No debe confundir nuestro análisis el hecho que se sostenga, predominantemente, que la acción judicial tiene una naturaleza abstracta, según la cual el demandante no tiene un derecho a obtener una condena, una declaración o la constitución de un nuevo estado (Zanzucchi, 1947, p. 50; Montero, Ortells, y Gómez, 1994, p. 421), sino que solamente posee el derecho a impetrar el ejercicio de la actividad jurisdiccional para alcanzar alguno de esos fines. Desde esa perspectiva, fácilmente, y sin atención a los costos del litigio, deberíamos concluir que el privilegio de pobreza debería proceder incluso en este supuesto. La decisión en definitiva establecerá los derechos de los particulares y, por tanto, no podríamos limitar este beneficio por una decisión futura, por más probable que sea.

Pues bien, a pesar que el marco normativo no entrega mayores antecedentes ni se pronuncia al respecto (Ley 17.995 y DFL 995), las pautas de actuación internas de las Corporaciones de Asistencia Judicial señalan como derechos del usuario el de ser patrocinado y representado ante los tribunales cuando así lo determine un "análisis de viabilidad", así como a ser informado de las razones por las cuales no cumple los requisitos para que su caso sea materia de atención, lo que entiendo comprende un pronunciamiento sobre las escasas probabilidades de obtener un resultado favorable. Entendemos que lo anterior es la consecuencia evidente que la finalidad de las Corporaciones mencionadas no solo es prestar asistencia judicial (es decir, representar ante los tribunales a sus usuarios), sino que, también, prestar asesoría jurídica y, en ese rol, informarán de las probabilidades, riesgos y cuestiones jurídicas que atentan contra la viabilidad del ejercicio de la acción respectiva. Esa labor reduce las asimetrías de información que tienen las personas en temas jurídicos, generando bienes públicos.

De esta forma, la existencia de un programa de asesoría y asistencia judicial gratuita, coadyuva a evitar que no se presenten aquellas acciones que son socialmente deseables de incoarse. Evidentemente que lo anterior es más probable en el contexto de un sistema institucional de asesoría y asistencia a "quienes tienen poco", lo que supone una inversión pública en ese sentido. Sin embargo, esa asesoría y asistencia abarca a quienes se acercan al sistema gratuidad buscando asesoría, pero no aquellos que por "negligencia atencional" no concurren. Esto último constituye una problemática anterior al proceso que únicamente puede mejorarse con mayor información, por ejemplo, con la publicación de los índices de tasa de efectividad de la asistencia judicial gratuita, o con mayor divulgación de casos ganados por ese mecanismo de gratuidad, de modo que tal sistema adquiera una mejor reputación y pueda adquirir los beneficios de un JR.

\section{Al momento de rendir prueba}

Las consecuencias distributivas en contra "de quien tiene poco", en la medida que haya podido iniciar un proceso, también se reflejarán en la etapa probatoria. La imposibilidad de rendir prueba para superar el estándar de prueba, a causa de su desmejorada posición económica, acarreará una situación de indefensión. Un sistema de apoyo a la litigación a "quien tiene poco" es inefectivo, si no le permite rendir prueba para acreditar sus pretensiones y/o defensas. 
Los esfuerzos dogmáticos que buscan fortalecer el rol del juez como mecanismo de protección de derechos en la etapa probatoria resultan de escaso aporte. En efecto, la adopción de medidas de oficio, no importa una mejora sustantiva a la ayuda asociada a contar con defensa técnica (proporcionada por el privilegio de pobreza). Asimismo, la oficialidad podría alterar la carga de prueba por medio de una regla de carga dinámica de la prueba (en su fase de carga de producir prueba ${ }^{10}$ ), pero tampoco se trataría de una solución evidente dada la escasa recepción normativa de ese instituto y el hecho que no está predestinado para atacar directamente las consecuencias distributivas asociadas a diferencias económicas entre las partes.

Las soluciones requieren superar los mecanismos propios de un sistema de administración de justicia liberal, tal como el vigente con el CPC. Se requiere que el Estado directa o indirectamente invierta recursos para subvencionar la actividad probatoria de una "persona que tiene pocos recursos" en la medida que no pueda derrotar los obstáculos que su desmejorada posición supone para la actividad probatoria. En este contexto, la oficialidad y la carga dinámica de la prueba pueden ser complementos necesarios, pero no suficientes.

Es importante que en el tratamiento de los problemas distributivos asociados a la actividad probatoria se respeten las garantías de independencia e imparcialidad. El Estado, representado en el proceso por el juez, no puede tomar parte activa en la rendición de la prueba. En otras palabras, la inversión de recursos que tienda a reducir las consecuencias distributivas en contra de "quienes tienen poco", no puede significar que el Estado invierta en el juez para que éste realice o ejecute un medio de prueba que de otra forma (dada la carencia de recursos) no se habría llevado a cabo. Desde esta perspectiva, no corresponde que el juez adopte una posición en el proceso a favor de la parte que carece de recursos, por ejemplo, siendo más acucioso en las preguntas a ser realizados en una prueba testimonial, o valorando de diferente manera las impugnaciones documentales dependiendo de la parte que lo presente (Carrasco, 2017, pp. 204-205). Esto incentivaría que las partes introduzcan antecedentes que conduzcan a errores de sobre-inclusión, es decir, a errores que demuestren que ellos son "personas que tienen poco" cuando no pertenecen a esa categoría. De ocurrir esto último se aumentarán los costos administrativos en una discusión alejada de aquello que resuelve el conflicto.

Al momento de la ejecución

En la ejecución de una decisión también se generan problemas distributivos, principalmente porque en Chile la ejecución es una etapa administrativa donde la actividad jurisdiccional posee un rol garante pero no implicado en los actos que concreticen lo resuelto. La ejecución de las decisiones que producen efecto de cosa juzgada se puede realizar por medio de un procedimiento de cumplimiento incidental de las sentencias, o por medio de un juicio ejecutivo. En ambos casos, las medidas de apremio (embargo) corresponden a gastos que deben ser pagados a auxiliares de la administración de justicia, es decir esta etapa origina costos privados de litigar.

Las soluciones a los problemas distributivos de esta etapa provienen, en general, del privilegio de pobreza, ya que ese beneficio permite no solventar las actuaciones de los receptores que sean necesarias. Sin embargo, en la práctica la disposición de los auxiliares de la administración de justicia para prestar sus servicios (de modo gratuito) a quienes gozan de privilegio de pobreza, no es la misma que la disposición

10. La carga de producir evidencia se asocia a la manifestación de la carga de prueba en tanto colaboración en el proceso, debiendo probar quien se encuentre en mejores condiciones para esclarecer ciertos hechos que estén razonablemente bajo su disposición. Si esa exigencia no se cumple, el juez podrá formar un indicio en contra de quien no aportó debiendo aportar, en (Gianini, 2009, pp. 104-110). 
que muestran (en términos de agilidad y rapidez) a quienes pagan por sus servicios. Esto se agrava cuando las diligencias que deben realizar los receptores requieren de la contratación de terceros que no tienen ese deber como, por ejemplo, ocurre con servicios de transporte o de flete, donde la concretización de esas labores exige el desembolso de dinero de los ejecutantes, sin distinguir si poseen o no condiciones económicas para solventar esos costos.

Por otro lado, las reglas de ejecución también tienen consecuencias distributivas, las que surgen de manera más sutil. Por ejemplo, en nuestro sistema procesal civil, la regla general es que se pueda ejecutar una sentencia cuando se encuentre firme y ejecutoriada ${ }^{11}$, siendo la regla excepcional que procede la ejecución cuando las sentencias causen ejecutoria12, es decir, cuando existan recursos pendientes (Bordalí, Cortéz y Palomo, 2019, p. 41), como sucede con la casación, la que normalmente, no suspende la ejecución de lo resuelto por los tribunales sobre el fondo ${ }^{13}$. Una modificación de esas reglas se plantea en el Proyecto de Nuevo Código Procesal Civil (PNCPC), que pretende la introducción del concepto de sentencias de ejecución inmediata, es decir, que las sentencias definitivas de condena, una vez notificadas a todas las partes podrán ser cumplidas provisionalmente ${ }^{14}$.

¿Dónde surge el problema? En los perfiles de riesgo de los litigantes. En efecto, las personas adversas al riesgo valorarán relevante la probabilidad de revocación -por muy poco probable que sea- de la sentencia que aún no tiene el carácter de ejecutoriada, pero que se comprende dentro de aquellas que originan ejecución inmediata. Por tanto, no ejecutarán ninguna sentencia (Carrasco, Núñez, y Coronado, 2018, pp. 222-223). En cambio, las personas propensas al riesgo (aquellas que ven el proceso como una apuesta y que bajo ningún respecto deberían ser beneficiados por normas procesales, como son los $\mathrm{JR}^{15}$ ) sí harán uso de esas reglas de ejecución inmediata pudiendo, por ejemplo, forzar acuerdos que de otro modo no se alcanzarían y que ponen a los sujetos JO (cuando son sujetos pasivos perdedores en primera instancia) en peor posición que frente a la inexistencia de esa regla. De esta manera, una regla de ejecución inmediata podría no beneficiar ex ante a todos los sujetos (favorece a los propensos al riesgo y tienden a favorecer más probablemente a los JR), no constituye una norma que sea adscrita impersonalmente por todos y, por tanto, no es óptimo paretiano (los perjudicados con esa regla no la aceptarán), y finalmente, si se favorece a JR en desmedro de JO, se producirán consecuencias distributivas indeseables.

Al momento de la generación del precedente

Las desigualdades al momento de iniciar un proceso también se expanden a la generación de precedentes. Las decisiones de los tribunales dependen de los asuntos que se litigan ante ellos. Es probable, a su vez, que esos asuntos surgen de ciertos $\mathrm{JR}$, es decir de litigantes que concurren sucesivamente a los tribunales por un mismo tipo de conflictos.

Es diferente la manera en que un JR y un JO enfrentan un litigio. Uno de los factores de los cuales dependerá el rol en el juicio, corresponde a si el proceso enfrenta a un JR con un JO, a dos JO, o bien, a dos JR. Nos concentrémonos en el enfrentamiento de un JR con un JO, porque en este escenario se pueden producir mayores consecuencias distributivas en contra de "quien posee poco" y sea un JO.

11. Esas sentencias producen acción de cosa juzgada, artículos 175, 176, y 231 del CPC.

12. Artículo 231 del CPC

13. Artículo 773 del CPC.

14. Artículo 234 del PNCPC

15. Que pueden visualizar como mejor información y más certeza las probabilidades involucradas, de modo que, podrían usar con mayor posibilidad esa regla de ejecución. 
Al respecto, es excepcional que una persona con dificultades económicas pueda ser un JR en materia procesal. El acceso a la justicia constituye un bien que no será demandado recurrentemente. Vimos que incluso el acceso a la justicia es un bien que, en ciertos supuestos, se encuentra fuera del alcance de "quienes tienen poco", incluso a pesar de tratarse de un bien, que pudiera ser, necesario. Por tanto, cuando un JO se enfrenta a un JR se generarán una serie de consecuencias distributivas que perjudican al primero.

En primer lugar, el JO puede beneficiarse de un cierto reconocimiento o "buena fama" que los tribunales suelen otorgar a quienes habitualmente concurren ante ellos (efecto reputacional). Este efecto puede no existir si los JR tengan una "mala fama". Con todo, esto último será lo excepcional porque los JR considerarán como parte de su estrategia de litigación invertir lo necesario en crear una buena reputación. Como demostración de este efecto en ciertos sub-conjuntos normativos, se ha señalado que la reputación de los JR explica parte las decisiones a favor de ellos. Se ha señalado como ventajas de los JR la oportunidad que tienen para desarrollar relaciones informales con la administración de justicia, pudiendo establecer y mantener una mayor credibilidad como litigante (Galanter, 1974, p. 107, 98-101). Ese efecto ha sido estudiado superficialmente en algunas áreas jurídicas en Chile (Pardow, 2015; para un estudio más completo: González y Micco, 2014). Tales decisiones, explicadas por el efecto reputacional, van generando señales para casos futuros (ya sea que exista un sistema judicial casuístico o consecuencialista) que indudablemente beneficiarán al JR más allá del caso concreto el precedente se dictó.

En segundo lugar, los JR litigarán las normas sustantivas con mayor propensión que los J0. De esa manera, tendrán más oportunidades para generar una interpretación favorable a sus intereses. Así, cuando interviene un JO sus posibilidades de incidir en una determinada visión sobre la norma en cuestión tendrá que derrotar un entendimiento que potencialmente viene configurado por la posición que hayan planteado los JR en una serie de casos anteriores. Esto genera una tendencia que favorece, en el largo plazo, las posiciones de los JR, quienes invertirán en los litigios futuros del área de su interés. Es lo que sucede con las compañías de seguro (el prototipo de un JR) se trata de un jugador procesal que tiene estrategias de largo plazo en donde utiliza los procedimientos para señalizar comportamientos futuros. De esta forma, para esas empresas las decisiones judiciales tienen un valor que excede el beneficio en el caso concreto porque el verdadero beneficio que deriva de ellas es la señalización referida. Por lo mismo, tiene el incentive a invertir fuertemente en decisiones favorables que tendrán efectos relevantes en el mercado de manera general (Cabrillo, 1989, pp. 107-108).

Así, existe un gasto de recursos dirigido estratégicamente hacia modelar las interpretaciones que gobiernan esas reglas (en el ámbito judicial), o bien, a instar por cambios de esas reglas (en el ámbito legislativo). Esta última posibilidad de incidir a nivel legislativo (vía creación de nuevas reglas) puede deberse por las dificultades que supone la modificación del sentido de las normas por medio de su aplicación judicial (Howard, 1969). En efecto, los tribunales (en sistemas como el chileno) ejercen un rol más reactivo que proactivo en lo referente al estatuto que aplican (Ruiz Tagle, 1990, p. 142; Damaska, 1986, pp. 77-80, 84-88), es decir desarollan una actividad hermenéutica más centrada en el caso concreto y en el sentido y alcance de las palabras de la ley (Atria, 2007, p. 44), que en la creación de pautas normativas para regir comportamientos futuros (Cooter y Ulen, 2008, pp. 643-644). Esa actividad limitada a una visión estática de la ley, se demuestra en la tendencia dogmática contra el activismo judicial (Verdugo, 2013). 
Además, la posibilidad de alcanzar acuerdos durante un juicio puede explotar las desventajas de "quienes tienen pocos" y, además, conduce a limitar la posibilidad del cambio de ley, que pudiera ser querido por un JO. En efecto, si el JR ve escasas posibilidades de obtener un buen resultado en juicio y como puede construir una estrategia minimax (minimizar la máxima pérdida), dado su conocimiento experto en el área jurídica en cuestión, surge la posibilidad del acuerdo como una manera de no alterar el sentido y alcance de la norma por medio de una decisión que visualiza negativa (Galanter, 1974, pp. 101-103; 135-139), cediendo en el caso en particular para evitar una mayor pérdida en el largo plazo.

Finalmente, el acceso a la jurisprudencia o precedente producido en la litigación de ciertos sub-conjuntos normativos donde intervienen JR, se erige como un costo adicional a ser gastado por el JO. En este sentido, en la fórmula [1], la inversión para medir las probabilidades de ganar o perder de un JO, serán mayores que para un JR. Si bien esta asimetría de información puede ser reducida por medio de la intervención de abogados (sobre reducción de asimetría de información en áreas particulares: Ross, 1970, p. 193; Mosier y Soble, 1973), de todas formas, subsiste una consecuencia distributiva en contra del "litigante que tiene poco" en tanto no puede acceder a aquellos abogados que habitualmente litigan en tales áreas jurídicas y que están mejor preparados para esos conflictos, suponiendo especialización negativa (Galanter, 1974, pp. 114-119). Una potencial solución a este problema concreto será examinada cuando tratemos los remedios distributivos asociados a la legitimación extraordinaria.

\section{Formas de solución a las problemáticas de tener poco en el proceso civil}

\section{Algunas palabras sobre los mecanismos liberales}

Es posible encontrar en la ratio legis de ciertas normas liberales una preocupación por el desbalance de condiciones económicas entre dos sujetos, al favorecer, de alguna forma, la posición de la parte económicamente más débil. La tradición liberal contempla ejemplos de esta forma de solución al problema de tener poco. De hecho, el Código Civil chileno (CC) establece reglas de presunción de culpa (artículo 2329), que libera de la carga de acreditar el elemento subjetivo necesario para configurar la responsabilidad extracontractual. Respecto de esa norma se ha señalado que contiene "... casos donde los hechos dañosos demuestran por su solo acontecimiento que lo más probable es que haya habido culpa; los hechos por sí solo son demostrativos de culpa" (Schiele y Tocornal, 2010, p. 124). Tal norma, vendría a contemplar supuestos especiales para enfrentar actividades productoras de daño (insertas en un mundo de riesgo), donde es probable que se produzca responsabilidad como consecuencia del desempeño y ejecución de tales actividades.

El supuesto típico en donde esa norma rige como mecanismo distributivo, supone, por una parte, que normalmente quien realice una actividad peligrosa la llevará a cabo con miras a obtener un beneficio que compense los costos que sus acciones pueden producir; y, por otra parte, quien sufra las consecuencias dañinas será un consumidor o cliente que no obtiene réditos como consecuencia de esas acciones. En esa categorización surgirán consecuencias distributivas si es que son importantes las diferencias patrimoniales entre ambos sujetos. Esas diferencias pueden ser preexistentes al daño, o bien, producidas como consecuencia del hecho que origina la responsabilidad. Un factor dependiente relevante es la capacidad patrimonial del sujeto afectado. De ocurrir esto último, entonces, la norma de presunción de culpa 
producirá beneficios a favor del sujeto dañado. El éxito de su acción, en el contexto del artículo 1698 CC, dependerá de una menor carga probatoria frente al escenario de tener que acreditar la culpabilidad del hechor ${ }^{16}$. El demandante, finalmente, ganará acreditando una menor cantidad de hechos primarios que en un conflicto donde no esa presunción, salvo, que el demandado no acredite las eximentes a la aplicación de la presunción.

Sin embargo, es fácil advertir las desventajas de resguardar las diferencias distributivas en contra de "quien tiene poco" por este mecanismo.

En primer lugar, como toda norma legal, se encuentra establecida de manera anticipada para regular situaciones genéricas con prescindencia de las diferencias distributivas concretas entre dos litigantes. Por tanto, la regla podría beneficiar a quien no se encuentre en una situación patrimonial desmejorada, o bien, podría la víctima del hecho dañoso estar en mejor condición económica que el victimario, anulando cualquier pretendida consecuencia distributiva.

En segundo lugar, la norma de presunción de culpa es derrotable. 0 sea, el victimario puede demostrar en el proceso ciertos supuestos fácticos que hacen improcedente la presunción. Esto se debe a que el artículo 2329 CC, solamente invierte la carga de la prueba, sin impedir que el victimario acredite su exculpación. Incluso en ese escenario excepcional, será el mismo bienestar económico del victimario lo que le ayudará a encontrarse en mejor posición para cumplir con la carga de prueba que le pesa. Lo anterior, porque normalmente ese victimario tendrá mejor conocimiento de los procesos productivos, tecnológicos, u otros que produjeron el daño. De esta forma, podrá hacer valer esa asimetría informativa a su favor, en un eventual juicio, siendo muy difícil que la víctima desmejorada pueda replicar, cuestionar u objetar ese esfuerzo probatorio de exculpación. En otras palabras, en la práctica es probable que la norma de presunción sea derrotada.

En tercer lugar, su ámbito de aplicación queda restringido a los casos excepcionales donde el legislador haya contemplado reglas de inversión de la carga de prueba a causa de normas con fines distributivos. Este es un problema real, máxime si esas normas son escasas y se interpretan restrictivamente (Bravo, 2013). Es así como, paradójicamente, la excepcionalidad de las normas de inversión se funda en el principio de igualdad en el tratamiento de las partes (Herrera, 1991, p. 43).

Finalmente, este mecanismo no es monopolio de regulaciones liberales. De hecho, normas procesales con un fundamento económico y social más intervencionistas, también recurren a regulaciones similares. Así sucede en materia de libre competencia, donde la letra b) del inciso $2^{\circ}$ del artículo 39 del DL 211, consagra la facultad de representación judicial que corresponde al Fiscal Nacional Económico, señalando "Serán atribuciones y deberes del Fiscal Nacional Económico: (...) b) Actuar como parte, representando el interés general de la colectividad en el orden económico, ante el Tribunal de Defensa de la Libre Competencia y los tribunales de justicia, con todos los deberes y atribuciones que le correspondan en esa calidad". Es importante precisar que la Fiscalía Nacional Económica no tiene el monopolio de la acción contenciosa de libre competencia (artículo 20 inciso $2^{\circ}$ del DL 211). Lo relevante es que, para posibilitar la debida ejecución y aplicación de la normativa de libre competencia, es necesario que el Estado invierta en la creación de un órgano que posea esa legitimación o

16. El artículo 1698 inciso $1^{\circ}$ del Código Civil impondría la carga de probar las afirmaciones fácticas constitutivas de su pretensión. Sin embargo, a causa de la presunción de culpa, no entraría dentro de las proposiciones de prueba a acreditar, el referido a la culpabilidad del demandado. La carga de derrotar esa presunción sería del sujeto pasivo. 
representación del interés general, sobre el entendido de una adecuada defensa de esos intereses no puede lograrse dejando esa actuación únicamente a los privados afectados (González, 2007, p. 8).

Asimismo, en materia laboral el legislador es consciente de las debilidades de este único mecanismo, estableciendo diversos complementos funcionales y orgánicos para hacer más efectiva la preocupación distributiva. Lo anterior, se logra con ciertos principios que protegen a la parte más débil (Gamonal, 2013; Munita, 2014), o bien, con la creación de una justicia especializada que tiende a una mayor sensibilidad por las diferencias subyacentes entre las distintas categorías de sujetos, resolviendo con un sesgo a favor de los trabajadores (Ruay, 2015), lo que pudiera estar constituyendo situaciones de activismo judicial (Ruay, 2014); o, finalmente, en normas de protección a los trabajadores por vulneración de sus derechos fundamentales, como el artículo 493 del Código del Trabajo que establece una facilidad probatoria para el demandante trabajador (Ugarte, 2009).

\section{Subsidios de costos}

Una característica de los mecanismos liberales es que no significan un costo para el Estado. No existe desembolso público para afrontar las consecuencias negativas asociadas al problema distributivo en contra de "quienes tienen poco". Por contrapartida, los mecanismos que deseo analizar en este apartado dicen relación con algún nivel de inversión estatal con miras a afrontar lo pernicioso que puede ser, para alguna de las partes que carece de recursos, el acreditar sus pretensiones o defensas.

Estos mecanismos de inversión estatal a favor de alguna parte desmejorada económicamente se basan en una idea de solidaridad social que justifica que con cargo a rentas generales se beneficie a un sector de la población (litigantes que carecen de recursos para llevar a cabo su actividad probatoria de manera efectiva) por medio de un subsidio en los costos privados de litigar.

Ese subsidio supone que el Estado se hace cargo de un gasto que de otro modo habría sido asumido por el litigante privado. Los casos que queremos examinar dicen relación con la rendición de prueba. Allí, el subsidio estatal se focaliza en tal etapa de la actividad probatoria porque, de otra forma, no podría cumplirse la promesa de un ejercicio jurisdiccional basado en la protección de derechos o intereses jurídicos. De no existir subsidios habrá un cumplimiento formal del ejercicio de la jurisdicción, incurriendo en supuestos de indefensión procesal, la que ha sido definida como "(...) la privación o limitación de las posibilidades esenciales del derecho de defensa-alegación y/o prueba" (Díez-Picazo, Borrajo, y Fernández, 1995, p. 100).

Desde esta perspectiva, es indefensión tanto restringir de manera esencial o no dar espacio para plantear las excepciones o defensas de las partes durante el proceso (indefensión en la alegación) (Carrasco, 2006, pp. 50-52), como cuando habiendo planteado esas alegaciones, se hace inefectiva la posibilidad de rendir prueba por decisiones adoptadas en el proceso (indefensión en la actividad probatoria). A esta última le daremos el calificativo de indefensión probatoria débil y es a la que los autores se refieren habitualmente (Hunter, 2010, p. 216). Sin embargo, esa indefensión probatoria no dice relación con la inefectividad en la actividad probatoria por razones extraprocesales como la incapacidad económica de la parte cargada con la prueba. A esta última indefensión probatoria la calificaremos como fuerte. 
La diferencia entre ambas indefensiones no es solo conceptual. Esa diferencia también refiere al nivel de inversión para evitar incurrir en alguno de sus supuestos. Para evitar la indefensión probatoria débil no se requiere un gasto adicional por el Estado, bastando un procedimiento que entregue herramientas suficientes para que no se verifique una privación o limitación de la actividad probatoria. Un mecanismo en ese sentido es el inciso $2^{\circ}$ del artículo 326 del CPC que señala que es inapelable la resolución que dispone la práctica de alguna diligencia probatoria, estableciendo una preferencia valorativa a favor de la rendición de medios de prueba, limitando el espacio para esa clase de indefensión. El PNCPC también parece tener un entendimiento de la indefensión como infracción a la igualdad de trato de las partes. Así, su artículo 118 se trata el requisito de trascendencia de la ineficacia de los actos procesales, indicando que el perjuicio (fuente de indefensión) ocurrirá cuando haya una inobservancia de las formas o exigencias legales que impidan a alguna de las partes ejercer sus derechos en el procedimiento. Además, su artículo 381 letra b), entiende que las partes quedan en indefensión cuando "no se hubiere respetado los derechos y garantías procesales de las partes".

Sin embargo, respecto de la segunda forma de indefensión las normas puramente procedimentales no son suficientes. Para evitar la concretización de esa indefensión se debe influir en la capacidad económica del demandante [factor $W$ de la ecuación 1]. Recordemos que ese factor viene dado con anterioridad al proceso y si es menor que los costos económicos del juicio [factor $\mathrm{Cl}$ ], dentro de los que se encuentran los gastos probatorios, entonces, no tendrá sentido la posibilidad de realizar actos alegatorios y de ofrecimiento de prueba en términos apropiados y oportunos. Así, para que la política pública evite esta indefensión requiere transferencia de recursos (directa o indirecta) a la parte económicamente débil para que afronte aquellos pagos que su capacidad no puede.

Al respecto, en Chile se contempla algunos casos paradigmáticos y relativamente recientes de subsidios procesales de naturaleza probatoria. Un ejemplo lo constituye el financiamiento estatal de las pericias biológicas en casos de filiación. Así fue establecido en las modificaciones del año 1998 al CC, permitiendo que el juez ordene la realización de esas pericias gratuitamente (Ley N 19.585, publicada en el Diario Oficial el 26 de octubre de 1998, específicamente en la introducción del título VII del Libro I del Código Civil sobre filiación), lo que se complementó con normas de asignación de valor probatorio a la reticencia a realizarlas ${ }^{17}$. Esos exámenes se realizarán en el Servicio Médico Legal cuando las ordene un tribunal, pudiendo ser costeados por los involucrados en laboratorios privados cuando deseen realizar estudios de paternidad en forma privada (Lagos, Poggi, y Mellado, 2011, pp. 546-547).

Un segundo caso corresponde al inciso $3^{\circ}$ del artículo 42 de la Ley 20.600 que creó los tribunales ambientales. Esa norma dispone la regla general de que los peritos serán financiados por cada parte. Sin embargo, excepcionalmente "... el Tribunal podrá eximir a la parte, total o parcialmente, del pago del honorario del perito cuando considere que ella no cuenta con medios suficientes para solventarlo. En este caso, el Tribunal regulará prudencialmente la remuneración del perito, teniendo presente los honorarios habituales de la plaza y el porcentaje de la remuneración que no fuere pagada por el solicitante. La cantidad asumida por el Tribunal será de cargo fiscal. Para lo anterior, el Tribunal requerirá contar con disponibilidad presupuestaria para dichos fines". Esta norma había 17. La Ley N²0.030, publicada en el Diario Oficial el 5 de julio de 2005, modificó el Código Civil y, en específico, su artículo $1^{\circ}$, entre otras cosas, reemplazó el inciso segundo del artículo 199 en el sentido de permitir que el juez de a las pruebas periciales, por si solas, valor suficiente para establecer la paternidad o la maternidad, o para excluirla. Asimismo, se estableció que la negativa injustificada de una de las partes a practicarse el examen hará presumir legalmente la paternidad o la maternidad, o la ausencia de ella, según corresponda. 
sido largamente solicitada por la doctrina (Bordalí, 2004, pp. 409-411), y constituye un caso de financiamiento estatal de pericias (Bordalí, 2016, p. 194). Lo relevante es que dado el costo que supone para el Estado el financiamiento de estas pericias, es que el tribunal podrá hacer partícipe del subsidio al mismo perito, el que, por ese solo hecho verá determinada su remuneración de manera judicial.

La norma establece una regulación adecuada en términos de incentivos. Por una parte, no perjudica la dedicación del perito, porque la modificación en sus condiciones de pago, operará ex post, sin que pueda reducir su esfuerzo a consecuencia del eventual menor pago que pudiera significar una tarifa judicial. Por otra parte, que exista un financiamiento determinado supone que las remuneraciones se ajustarán a esa restricción presupuestaria, obligándose a un uso razonable y apropiado de este mecanismo. Esto es relevante porque existen aprehensiones sobre el encarecimiento de los costos que implican estas actividades por parte del Estado, según se ha podido detectar en ciertos conflictos ambientales (Astorga et. al., 2017, pp. 41-42).

Finalmente, en el PNCPC se contempla que ciertas pericias serán de cargo de organismos estatales. En este sentido, una norma que afronta directamente las problemáticas distributivas para no generar indefensión procesal es el inciso $4^{\circ}$ del artículo 324. que dispone que cuando una parte haya acreditado que "carece de los recursos necesarios para pagar los honorarios del perito", el juez podrá solicitar la elaboración de un informe pericial a un organismo público o que reciba aportes del Estado, en la medida que se considere indispensable para la adecuada resolución del conflicto. Esta norma es susceptible de algunas mejoras. Por lo pronto, debería establecerse que aquellas personas que gocen de privilegio de pobreza se entiendan las personas beneficiadas, quedando la carga de acreditar la condición que establece la norma a otras personas que no tengan ese privilegio. Adicionalmente, se necesita precisar a qué refiere que el organismo reciba aportes del Estado, porque esa redacción podría incluir entidades privadas que reciben financiamiento público vía subsidios, subvenciones, $u$ aportes fiscales. Finalmente, creo que la norma establece un adecuado uso de los recursos públicos, ya que más que recurrir a un presupuesto adicional, hace uso de las economías de escala de los organismos que emitirán el peritaje, ya que se trata de entidades que por su función de producción, especialización y experiencia pueden realizar tal labor a un bajo costo marginal. Finalmente, este mecanismo de subsidio es más eficiente que el contemplado en materia medioambiental, porque genera menos externalidades negativas (no obliga a un tercero distinto de quien da el subsidio a soportar parte del costo de la política distributiva) y, aprovecha economías de escala. En otras palabras, pudiera no ser demasiado costoso, en tiempo y trabajo, llevar a cabo esas pericias en la medida que se solicite un encargo que encaje dentro de las funciones y especialización asociada al organismo respectivo.

\section{Legitimación extraordinaria y reglas similares}

Las reglas de legitimación extraordinaria ${ }^{18}$, así como otras instituciones similares, son otras formas de solucionar los problemas distributivos en el proceso. Desde esta perspectiva, la fuente de imposición de esta legitimación extraordinaria es la ley, ya sea, de manera inmediata, o bien, mediata. Será inmediata cuando la ley expresamente contempla que determinada persona, natural o jurídica, representará los intereses de otra. Será mediata, cuando la ley autoriza a una autoridad determinada (normalmente, judicial) para establecer esa posición legitimante.

18. Aquellas que la ley otorga a personas ciertas o indeterminadas para que tengan una posición legitimante en un proceso sin que el legitimado extraordinario afirme su vinculación con la relación sustantiva subyacente, la que corresponde a otro por quien actúa. 
Dado el carácter excepcional de este instrumento existen una serie de principios o características que le dan contorno. En primer lugar, el ámbito de extensión y facultades de la legitimación se encuentra delimitado en la ley (principio de legalidad). Asimismo, estas reglas no excluyen la actuación del representado, quien no es privado de la potencialidad de actuar en el mismo ámbito de atribuciones conferido al representante. Lo relevante, con todo, es que el representante no requiere de una expresión determinada de voluntad del o de los sujetos representados para ejercer sus funciones (principio de no exclusión). Finalmente, el representante asume una responsabilidad no sujeta a una rendición de cuentas a cada representado. Dado que los sujetos representados son indeterminados, resulta imposible establecer una carga de rendición de cuenta particular. De otra forma, se perdería gran parte de los beneficios de este mecanismo (principio de legitimación o representación sin rendición de cuentas).

Algunas de estas reglas tienen una raigambre liberal. Fueron establecidas en el CC, y en el CPC. Los casos paradigmáticos son la acción popular en los casos de daños contingentes que por imprudencia o negligencia de alguien se amenace a personas indeterminadas o a personas determinadas (artículo 2333 CC), en cuyo caso, el actor será indemnizado de todas las costas de la acción y se le pagará lo que valga el tiempo y diligencia empleados (artículo 2334 CC). Asimismo, puedo mencionar los casos de acciones posesorias especiales con acción popular (artículos 948 a 950 CC, y artículo $582 \mathrm{CPC}$ ), donde el actor puede ser recompensado a costa del demandado de una suma que no baje la décima, ni exceda la tercera parte de lo que cueste la demolición o enmienda, o bien, el restablecimiento del daño, más la mitad de la pena pecuniaria asociada.

Tales reglas no suponen inversión pública para hacer más probable la presentación de pretensiones en ciertos ámbitos donde es escaso el beneficio privado de iniciar una acción. Más bien, otorgan la calidad de potenciales demandantes a todos los miembros de la comunidad, incentivando que inicien acciones una vez que valoren las probabilidades de obtener un resultado favorable y la cuantía de lo reclamado. En efecto, esos factores (probabilidad de ganar y cuantía de lo reclamado), permitirán según el incentivo de racionalidad subyacente en la norma, que haya personas que se interesen por el inicio de tales acciones. En el largo plazo, si esas personas son exitosas pueden transformarse en JR, donde los costos asociados al inicio de la acción se disminuyan por la experiencia en esas áreas de litigación. Ese resultado beneficioso para la comunidad (por el inicio de acciones socialmente deseables) y para los privados (cuyas rentas emanarán del inicio de tales acciones), en una visión liberal del litigio, entregará incentivos suficientes, sin que el Estado gaste un solo peso. Sin embargo, existe la sensación que esas normas son escasamente usadas y poco efectivas. Asimismo, no se han creado organizaciones privadas con el objeto específicos de explotar la posibilidad de negocios que emanaría de esas normas. Finalmente, el ámbito de aplicación de esas reglas y de su incentivo, depende de la magnitud de los beneficios que pueden alcanzarse con esas litigaciones.

Esto último puede ser desilusionante si en Chile las reglas de costas (como ocurre con el artículo 2334 CC), dependen de la discreción judicial, lo que no entrega ningún incentivo ${ }^{19}$ (para negociar, ir a juicio, presentar demandas meritorias, etc.), como lo hace el sistema inglés donde quien pierde paga sus costas y las de la parte ganadora, o el sistema americano donde cada parte paga sus costas (Huerta, 2012; Katz,

19. En efecto, a pesar de que la parte sea totalmente vencida es posible que no sea condenada en costas si es que los tribunales la eximen por tene motivo plausible para litigar (artículo $144 \mathrm{CPC}$ ). La jurisprudencia no ha delimitado ese concepto. El artículo $145 \mathrm{CPC}$, contempla una regla similar para las sentencias dictadas en segunda instancia, sobre la que tampoco existe mayor claridad. 
1990, pp. 17-19). El sistema chileno es ineficiente y hace perder a las costas todo sentido de disuasión, sanción o de (des)incentivos. Lo mismo sucede con parte de los beneficios asociados al ejercicio de estas acciones populares, como sucede con la promesa normativa de ser remunerado de la mitad de la "pena pecuniaria" (artículo 948 CC), concepto que no posee una delimitación clara (Barros, 2006, p. 874). Lo anterior, hace difícil el cálculo del posible beneficio que se puede obtener del ejercicio de la acción ${ }^{20}$, el que no tendría un fin resarcitorio. Asimismo, la jurisprudencia se ha manifestado dubitativa en conceder lo que "valga el tiempo y diligencia empleados" (artículo 2334 CC). Por ejemplo, en un estudio (Díez, 2016) se dieron a conocer dos sentencias que se pronunciaron sobre esas prestaciones señalándose que en uno de ellos se fijó una indemnización por concepto de tiempo y diligencias empleados en el ejercicio de la acción (sentencia definitiva pronunciada en causa Rol 1675-2006, seguido ante el $2^{\circ}$ Juzgado Civil de Concepción), pero en el segundo caso se omitió ese pronunciamiento (sentencia definitiva pronunciada por la Corte de Apelaciones de Santiago, en causa Rol 7396-2014).

Los mismos defectos mencionados respecto de las normas de inversión del onus probandi, aplican en la especie. La legitimación no se entrega a un ente, creado para los efectos de asumir ese rol, sino que la posición legitimante se distribuye en todas las personas. El Estado no asume ningún costo al establecimiento la norma, sino que deja a los sujetos la valoración de asumir o no la calidad de representante para actuar en interés de otros.

Como señalamos, la efectividad práctica de esta solución liberal ha sido escasa, tanto que legislaciones especiales han consagrado regímenes de legitimación o representación no-liberales, que han suplido ámbitos de aplicación de tal institución. Entendemos por tales regímenes no-liberales aquellos que suponen la participación del Estado en la creación, financiamiento y puesta en ejecución de entes con la facultad específica de representar intereses colectivos, o bien, donde el Estado los acepta, ampara y, eventualmente, subsidia ${ }^{21}$. 0 sea, se trata de entes que se encuentran habilitados para iniciar una demanda en defensa de los intereses de un cierto colectivo, lo cual no obsta que los tribunales ejerzan un control acerca de la concurrencia de los requisitos que habilita su comparecencia o que pueden valorar si poseen la representación suficiente (Aguirrezabal, 2010, pp. 184-187). Con todo, en ciertos casos, ese control no puede ejercerse por los tribunales, porque el estatuto legal orgánico se lo asigna de manera inmediata al ente administrativo, como ocurre con la FNE en sede de libre competencia.

La lógica de ese financiamiento estatal es reducir el problema distributivo, más patente en contra de "aquellos que poseen poco", a saber: la sub-litigación de asuntos que los perjudican debido a que el costo del reclamo de una conducta ilícita es mayor que el beneficio individual que ese reclamo traerá consigo en el evento de obtener una decisión favorable, sea reparatoria, compensatoria o puramente declarativa.

El surgimiento de organizaciones que representen intereses colectivos tiene la bondad de hacer surgir grupos de sujetos con la habilidad de actuar de forma coordinada, a largo plazo, con mayor experiencia y capacidad de entregar servicios legales de mejor nivel (Galanter, 1974, pp. 141-143). En otras palabras, esas asociaciones se transformarán en JR, estableciendo incentivos para las "personas que tengan poco" 20. Los artículos 149 a 156 del Decreto N 458, de 18 de diciembre de 1974, del ministerio de Vivienda y Urbanismo, publicado en el Diario 0 ficial de 13 de abril de 1976, que fijó el texto refundido de la Ley General de Urbanismo y Construcciones, y que tratan la demolición de parte o de todo de un inmueble que amenaza ruina, cuando esa solicitud emana de un tercero no propietario, y que regula la situación del artículo 948 del Código Civil, tampoco entrega ninguna pauta para clarificar ese concepto.

21. El artículo 11 bis de la Ley 19.496, establece un fondo concursable destinado al financiamiento de iniciativas que las Asociaciones de Consumidores desarrollen en el cumplimiento de sus objetivos. 
que son JO, en tanto podrán soslayar las dificultades distributivas que enfrentan adversamente al litigar con un JR. Con todo, es crucial que las asociaciones que representen intereses colectivos como JR adquieran cierta credibilidad. Como se trata de asociaciones voluntarias de personas, la credibilidad no solamente es aquella que se construye hacia los tribunales o agencias estatales frente a los cuales actúa y que resuelven sus peticiones o acciones, sino que, también, refiere de una credibilidad asociada a su capacidad para administrar reclamos y utilizar información de manera transparente, de forma que las personas JO se sientan motivadas para participar en una asociación que pueda transformarse en un JR.

Un mecanismo de política pública adicional es la creación de entidades estatales que representan ciertos intereses colectivos. El fundamento para su creación pasa por la necesidad de administrar ciertos intereses que no son disponibles y, por tanto, no deben recaer en privados. Esa falta de disponibilidad puede surgir de los riesgos de error que puede existir en la toma de decisiones relevantes, de forma que es más controlable su acción a nivel público, estableciendo una mayor gama de sanciones, ya no solo civiles, penales, sino también, administrativas. Si bien, tales entidades deben estar sujetos al escrutinio público es siempre deseable algún grado de autonomía a efecto de que prime su especialidad versus a los intereses públicos.

Finalmente, en esta materia puede mencionarse la situación de las class actions. En Chile existió la posibilidad de tener un sistema que integrara un procedimiento de mediación colectiva y, en caso que fracasara, se podía iniciar una acción en defensa del interés colectivo o difuso. Esa posibilidad estaba incluida en un Proyecto de Ley que modificaba la Ley 19.496, sobre Protección de los Derechos de los Consumidores ("PMLPC"). Tal proyecto contemplaba un procedimiento de mediación colectiva. Sin embargo, el Tribunal Constitucional, en la sentencia Rol N 4012-17-CPR ("sentencia del TC"), declaró inconstitucionales tales normas al conocer del control preventivo de constitucionalidad (Carrasco, 2018).

Es importante señalar que la LPC posee una regulación de class action, la que a pesar de reducir los costos de litigación hace poco atractiva la utilización de herramientas procesales para perseguir la infracción a las normas de protección al consumidor. Una posibilidad para mejorar el sistema era establecer mediaciones colectivas que estuvieran interrelacionados con los ya existentes procedimientos para la defensa del interés colectivo o difuso de los consumidores. En ese sentido, la reforma establecía el sistema integrado referido para reducir la cantidad de infracciones no reclamadas. La hipótesis de integración de instrumentos se fundamenta en que el LPC impedía el inicio de los procedimientos para la protección del interés colectivo o difuso una vez iniciada una mediación colectiva sobre los mismos hechos, o bien, la existencia de una mediación colectiva en presencia de un procedimiento para la protección del interés colectivo o difuso. La regulación propuesta se basaba en la racionalidad de los sujetos legitimados quienes deberían primero dar inicio a una mediación colectiva dado que son mecanismos alternativos de resolución de conflictos con menores costos que los procedimientos formales (Cooter y Ulen, 2008, pp. 602-608; Landes y Posner, 1979). Además, centrándonos exclusivamente en los consumidores afectados como legitimados de una mediación colectiva, sus costos de coordinación son menores en esas mediaciones que en el caso de los procedimientos para la protección del interés colectivo o difuso (siendo más fácil que se cumpla con las reglas de legitimación en el primero de esos instrumentos) ${ }^{22}$. De esa manera, el modelo integrado permitía institucionalizar las negociaciones asociadas a una class action. Además, la

22. Para poder iniciar un procedimiento para la protección del interés colectivo o difuso se requiere la reunión de 50 consumidores afectados; en cambio, para dar inicio a una mediación colectiva no se requería tal exigencia (artículo $1 \mathrm{~N}^{\circ} 45$ PMLPC en cuanto agregaba un artículo 54 H inciso 1 LPC) 
mediación colectiva constituiría un escenario de negociación cuya voluntariedad estaba condicionada por la amenaza de una class action posterior. Por tanto, de haberse declarado su constitucionalidad, esa amenaza sería más relevante que en la actualidad (con bajo número de procesos colectivos), generando mayor efectividad y uso de los mecanismos de protección colectivas de consumo y, por tanto, un mayor ingreso al sistema frente a un contexto de inexistencia de integración.

Por otro lado, el sistema integrado favorece consecuencias distributivas. En primer lugar, aminoraba el costo del acceso a la justicia para el consumidor individualmente considerado (normalmente, un JO). El fundamento de eficiencia se satisface cuando sea socialmente deseables permitir el ejercicio de acciones que de otra forma no habrían sido incoadas individualmente (dado sus costos). De esta forma, la class action aprovecha las economías de escalas de un sistema integrado (Kaplow y Shavell, 2002, p. 247). Esto lo podemos examinar a propósito del costo privado de litigar referente a los honorarios del abogado del consumidor afectado (Pastor, 2003, p. 47). Ese valor supone un costo fijo (salvo un acuerdo de honorarios a resultado), que al devengarse durante el proceso (antes de obtener la reparación), reduce la ganancia probable positiva de litigar y, por tanto, hace menos factible que esa ganancia supere el valor crítico de acceso a la justicia. Esos honorarios son un factor que desincentiva la litigación en comparación a un escenario donde ese elemento no concurre. En el caso de las class action, o, en un sistema integrado de protección colectivo de consumidores, los consumidores pueden aprovechar la actuación del Sernac, o bien, de Asociaciones de Consumidores, o finalmente, la actuación eventual de un grupo de consumidores, bastando que comparezcan sin necesidad de representación letrada ${ }^{23}$. Otra economía de escala relevante es el costo social de litigar relacionado con las implicancias que puede traer consigo la divergencia generadas por costos de agencia. El problema de la agencia se produce cuando una persona (principal) encarga a otra (agente) una determinada gestión, dejándole ciertos márgenes de discrecionalidad en la toma de decisiones, aceptando el agente actuar en representación de los intereses del principal. De esta forma, el principal no conoce el grado de esfuerzo real ni el acuerdo o eficacia del agente, sino solamente su resultado final. Para revisar un trabajo clásico sobre el tema (Ross, 1973, pp. 134-139).

Pues bien, esos costos son mayores en presencia de dos niveles de agencia. La alternativa a la actuación personal (como medio de reducción de los costos de litigar) produce sólo un problema de agencia (el que vincula al consumidor con el legitimado para actuar en su representación) y dos problemas de agencias (el anterior sumado al problema de agencia entre el consumidor con su abogado) y, con ello, se reducen los costos de coordinación y fiscalización dentro de los demandantes.

En segundo lugar, al aumentar la probabilidad de acceso a juicios de consumo ${ }^{24}$, se posibilitan mayores niveles de disuasión. Lo anterior, siempre que la falta de litigio (en un escenario sin class action, o, sin un sistema integrado) no genere disuasión por falta de detección y sanción de las conductas indebidas de los proveedores. Por tanto, cuando es pequeño el efecto de disuasión de una sentencia judicial sobre los niveles de cuidado de los proveedores, entonces, esos mecanismos no reducen el costo social de las conductas de los proveedores que subsisten impunemente dada la no detección ni sanción. Así, al aumentar la disuasión los proveedores sabrán que es más probable la detección de sus conductas, lo que debería reducir la cantidad de conductas indebidas en perjuicio de los consumidores. Si los servicios que ofrecen o 23. Incluso para los efectos de la efectividad de la acción frente al demandado, pudiera ser mejor la actuación personal del consumidor subsecuente que se hace parte del proceso, ya que será más probable que se reduzcan los costos de coordinación de la defensa letrada.

24. Esto es más factible con la agregación de reclamos individuales de escasa ganancia probable positiva y, por tanto, de escaso valor crítico de acceso a la justicia. 
prestan los primeros dicen relación con bienes de primera necesidad sobre los que existe una demanda inelástica de los consumidores, entonces, es probable que el aumento de la disuasión afecte a un JR, beneficiando a un $\mathrm{JO}^{25}$.

\section{Normas de limitación al propenso al riesgo}

Las personas se pueden vincular con el riesgo de manera diversa. Existen tres tipos de categorías, aquellos que son propensos al riesgo, los neutrales al riesgo, y los adversos al riesgo. De esos tres tipos de personas tendremos resultados diferentes en la aplicación de las normas procesales. Por ejemplo, sobre la posibilidad de ejecutar una decisión cuando causa ejecutoria, muy probablemente el propenso al riesgo procederá a ejecutar la decisión porque valorará el riesgo de una revocación de la decisión de manera mucho menos relevante de lo que hace el neutral y el adverso.

De la constatación anterior surge una primera complejidad ¿Las normas procesales civiles deben estar dirigidas a una persona neutral, propensa o adversa al riesgo? Se trata de una pregunta de difícil respuesta y que entiendo no ha sido formulada en la doctrina chilena.

Las dificultades de esta pregunta pueden ser divididas en, al menos, dos perspectivas. La primera es empírica, es decir saber cuál es el perfil de riesgo de la población sobre la que la norma procesal regirá. Desde esta perspectiva, las normas procesales deberían estar dirigida para adecuarse al perfil de riesgo de la mayoría de las personas. Esa sería una norma con potencialidad de ser efectiva, en tanto adecuada para la realidad donde se propone. Sin embargo, esta perspectiva tiene defectos. Primeramente, soslaya los fines que puede perseguir el procedimiento en cuestión (verdad, reducción de costos, resolución de conflictos, etc.), ya que atender al perfil de riesgo de la mayoría de las personas pudiera conducir a una disociación con los objetivos que se desea con las normas procesales. Eso ocurrirá si la mayoría de las personas son propensas al riesgo lo que llevaría a favorecer, una norma sobre lanzamiento de inmueble (haciendo apelable en el efecto devolutivo la resolución que la concede) en una legislación sobre arrendamiento que protege a los arrendatarios (dando plazos de gracias para la entrega del bien arrendado). Además, se es muy cara de implementar, necesitando recopilar antecedentes suficientes para catalogar a las personas en alguno de esos perfiles de riesgo, exigiendo estudios de campo de alto costo. Más aún, las preferencias de riesgo pueden ir mutando con los cambios de la población y, por tanto, que la eficacia de las normas procesales dependa de una mayoría de cierto perfil de riesgo, es solo una ilusión que requiere la subsistencia de esa mayoría.

La segunda perspectiva es dogmática, y busca entregar argumentos para determinar si es deseable que una norma procesal civil fomente o desaliente conductas de alguno de los perfiles de riesgo. Al respecto, existen razones para pensar que el comportamiento del propenso al riesgo no debería ser fomentado, ya que ese perfil conduce a una serie de externalidades negativa en el proceso civil.

Una de esas externalidades se verifica en la decisión sobre negociar o ir a juicio. De acuerdo a la teoría prospectiva, los escenarios de ganancias conducen a comportamientos adversos al riesgo y los escenarios de pérdidas conducen a comportamientos propensos al riesgo (Tversky y Kahneman, 1986). En un litigio, el sujeto que enfrentará un escenario de ganancias es el demandante y el sujeto que enfrentará un escenario de pérdidas es el demandado. En una negociación es más claro que la

25. Lo anterior, porque ello demostraría que esos bienes de primera necesidad no tienen sustitutos a bajo costo por los consumidores y si ello ocurre, es porque los consumidores no tienen suficiente presupuesto para comprar bienes sustitutos de mejor calidad. 
víctima o el sujeto que busca una compensación enfrentará alternativas de dominio positivo: si la negociación es exitosa la víctima recibirá una compensación que será una ganancia y, en caso que la negociación fracase, es probable que se mantenga en una posición similar en términos de riqueza de la tenía antes de las conversaciones con el victimario. En cambio, en un proceso, la víctima sujeto activo del juicio, puede ganar o perder y, en el primer caso, deberá asumir las costas, pudiendo resultar que sus alternativas sean mixtas, es decir de dominio positivo si gana el juicio, o de dominio negativo si pierde. Algo diferente ocurre con el victimario o sujeto pasivo, siendo difícil que en juicio ese sujeto enfrente alternativas que no sean de dominio negativo ya que la alternativa de perder supondrá pérdidas necesarias (incluyendo las costas); y si gana, muy probablemente tendrá que soportar sus propios gastos. Por su parte, en una negociación exitosa siempre deberá pagar algún monto a la víctima. Por tanto, en ambos escenarios enfrentará escenarios alternativos de dominio negativo.

Pues bien, el comportamiento propenso al riesgo reduce el espacio de negociación porque el monto que está dispuesto a ofrecer no alcanza el mínimo que el demandante (aún adverso al riesgo) está dispuesto a aceptar (Babcock, Farber, y Shafir, 1995, pp. 289-303; Rachlinski, 1996, p. 1369). Es decir, según esta teoría existirán menos acuerdos de aquellos que propone la teoría tradicional del análisis económico del derecho, de la utilidad esperada (Rachlinski, 1996, pp. 119-120) que enseña que los litigantes realizan decisiones adversas o propensas al riesgo dada la magnitud del interés comprometido en juicio en relación a su bienestar total (Cooter y Rutherfor, 1989).

Una consecuencia es que los litigantes nunca buscan deliberadamente el riesgo porque el demandante escogerá entre una ganancia segura si acuerda el caso, o bien una ganancia incierta pero más rentable si litiga; por su parte, el demandado escogerá entre aceptar una pérdida segura de alcanzar un acuerdo, o bien, una pérdida incierta y potencialmente mayor si litiga (Gould, 1973, pp. 291-293). Sin embargo, como señalamos la teoría prospectiva ha comprobado que los sujetos buscarán el riesgo si enfrentan escenarios de pérdidas, como acontece con el demandado, quienes estarán menos dispuestos a acordar que si no tuvieran ese perfil de riesgo (como advierte la teoría de utilidad esperada), por tanto, preferirán la mayoría de las veces la opción de probable pérdida mayor y se jugarán sus opciones por ello.

Pues bien, la externalidad se produce cuando ese demandado propenso al riesgo es un demandado JR (tiendas de retail, banca, instituciones financieras, proveedores, etc.), que pueden verse enfrentados, por ejemplo, a procedimientos en materia de derecho de consumo, de responsabilidad civil, o de prácticas de competencia desleal. En esos casos, si las víctimas de sus comportamientos son consumidores (es decir, J0), entonces, la propensión al riesgo de los JR conducirá a menores tasas de acuerdo y a mayor litigiosidad, cuyos costos pueden inducir a consumidores a no demandar. Incluso más, esos JR pueden influir en los costos de los consumidores de ejercer acciones en su contra (Menell, 1983), señalizándose como litigante temerario y persistente. De hecho, la celebración de conciliaciones puede entregar información al mercado acerca de un comportamiento débil que incentive mayor cantidad de acciones, lo que evidentemente será anticipado por el JR y reducirá toda imagen conciliadora. Esto incluso cuando existan condenas de las cuales se deriven efectos de prejudicialidad, como hemos visto con el acuerdo de indemnización por el caso de la colusión de las Farmacias, donde la reparación de indemnización de perjuicios ocurrió 8 años después que las cadenas farmacéuticas fueron condenadas en sede de libre competencia por sentencia firme y ejecutoriada. En efecto, la Excma. 
Corte Suprema, dictó sentencia de segunda instancia, el 7 de septiembre de 2012 , en causa Rol N 2.517-2012, que confirmó la Sentencia 119/2012 del TDLC de fecha 31 de enero de 2012. Después de un largo proceder ante la justicia ordinaria buscando indemnización de perjuicios, en donde las empresas condenadas en sede de libre competencia opusieron diversas estrategias legales para dificultar la indemnización, finalmente con fecha 11 de noviembre de 2020. Incluso más, ese acuerdo indemnizatorio no fue suscrito por la empresa Farmacias Ahumada que reconoció su participación en la colusión en la causa de primera instancia ante el TDLC (Rol 1416-2019), según consta en resolución de 13 de abril de 2009 aprobó conciliación entre esa empresa y la FNE.

Otra externalidad se relaciona con la fórmula $\left[1.4^{26}\right]$ en tanto señala que la introducción de un factor de propensión al riesgo conduce a mayor cantidad de juicios de los socialmente deseables. Además, esa mayor cantidad de procesos da cuenta de una auto-selección de quienes son los litigantes que inician tales juicios, lo que también supone problemas distributivos. En efecto, es más probable que quienes sientan mayor propensión (que el socialmente óptimo) al juicio, sean quienes no tienen una posición desventajada económicamente. Tales sujetos harán uso de un bien público de manera excesiva y con miras a satisfacer su único interés. En otras palabras, la divergencia entre el interés público y privado de litigar llega a su máxima expresión.

Además, el propenso al riesgo puede conducir a resultados contraintuitivos en ámbitos donde, por medio del proceso, se persigue aumentar la riqueza existente. Por ejemplo, las subastas que han sido estructuradas para que los derechos o bienes sean asignados a quienes posean la mayor disposición a pagar. He indicado que esa regulación intuitivamente es adecuada como mecanismo de disposición judicial de bienes, sin embargo, pueden fallar en su propósito (transformarse en una norma inefectiva) si no atiende a las posiciones que posibles oferentes pueden tener respecto del riesgo (Carrasco, 2019, pp. 89-92). En efecto, existirá una asignación del derecho o bien subastado a la persona que exprese una mayor disposición a pagar, lo que no significa que esa persona sea el titular de la mayor disposición a pagar considerando todos los perfiles de riesgo posible. Por ejemplo, una subasta inglesa, que termina cuando el bien es asignado al último en pujar luego de que nadie ofertara en las oportunidades anteriores (Binmore, 2011, pp. 156-159), favorece al propenso al riesgo porque neutraliza al adverso al riesgo que no pujará sino cuando pueda presenciar que su nivel de oferta es mayor a pujas ya realizadas. El problema es que una regla de subastas que favorezca al propenso al riesgo y no al adverso al riesgo, no permite alcanzar la finalidad de atrapar a la persona que está dispuesto a pagar mayor cantidad de recursos por el bien ${ }^{27}$. Ello se demuestra con las subastas de estilo holandés, donde se comienza ofertando un precio elevado y se va bajando gradualmente hasta que el comprador pide que se detenga, generará una mayor valoración del bien subastado, porque el adverso tenderá a participar más en esas subastas, y ofertará muy tempranamente, a pesar de que el valor del bien sea alto. Ello se explica porque el adverso al riesgo, teniendo presupuesto suficiente, valora más la asignación del bien que el riesgo de no ser el adjudicatario. 0 sea, la ansiedad se lo comerá y levantará la mano antes.

26. Pie de página 5 .

27. Esta inefectividad se aprecia en la legislación procesal civil, ya que mecanismo de subasta para bienes inmuebles implica que se debe aprobar una tasación que sirve en la generalidad de las subastas de piso mínimo para la subasta, la que deberá ser realizada por posturas sucesivas que van subiendo el precio del bien a adjudicar (artículo $493 \mathrm{CPC}$ ), hasta que solamente un postor puje por el último precio señalado por el juez. El PNCPC no consagra reglas que atiendan a las preferencias de riesgo de los destinatarios de las subastas ni establecen reglas que flexibilicen el mecanismo obligatorio legal de liquidación de bienes por medio de dar espacio a que el juez o los directamente interesados (fundamentalmente los acreedores) puedan consagrar mecanismos que permitan obtener mejoras en el valor del bien subastado. 
Finalmente, otra externalidad es que el propenso al riesgo conduce a aumentar los costos del juicio al hacer más posible que duplique la inversión probatoria de su contraparte. En efecto, dado que los demandados enmarcan sus alternativas en juicio como pérdidas, entonces adoptan decisiones más arriesgadas en el procedimiento, invirtiendo mucho más (en mejores abogados, en mayor actividad probatoria, incentivando conductas dilatorias, etc.), para aumentar las probabilidades a su favor de un resultado incierto. Algo similar ocurre con la regla de costas europea, según la cual quien pierde, gana. La que genera, en el demandado propenso al riesgo, una visualización de pérdidas de mayor valor, lo que conduce a investir de mayor manera para no sufrir esas pérdidas, aunque esa inversión no resulte rentable (Donohue, 1990-1991; Donohue, 1991). Adicionalmente, dado que las personas valoran más el cambio del estatus quo que la magnitud del cambio, entonces, el demandado que visualiza un empeoramiento de sus condiciones como consecuencia de la pérdida de un litigio, realizará actuaciones (incluso irracionales) con miras a fortalecer las probabilidades que tiene de no perder, lo que puede conducir a mayor inversión en juicio (Rachlinski, 1996, pp. 144-145). Una manera de fortalecer esas probabilidades es rendir una mayor cantidad de prueba para acreditar un hecho discutido en juicio. Lo que puede conducir a aportes sucesivos de prueba solo con miras a replicar a la contraria. Sin embargo, ello resulta ineficiente y tiene problemas distributivos. Es ineficiente porque el aporte sucesivo de evidencia reduce la utilidad marginal de cada aporte adicional, de forma que si un litigante desea agobiar a la contraria en materia probatoria, esa actividad va a consistir en mayores costos que beneficios; además, es ineficiente porque si la parte contraria busca igualar ese esfuerzo, entonces, el rendimiento marginal decreciente regirá para ambas partes, entregando al tribunal evidencia que únicamente busca sorprender y ganar por cantidad, más que por calidad, traduciéndose en un costo social adicional (Posner, 1998-1999, pp. 1480-1490). Por su parte, existen consecuencias distributivas, porque si en un proceso se enfrenta un JR con un JO, entonces, los últimos no podrán realizar esa actividad probatoria y lo que podría entenderse como una dejación de su interés en juicio, favoreciendo así la posición de quien tiene mayor capacidad económica para aportar evidencia, lo que puede reforzar la imagen reputacional que normalmente construyen los JR.

Si llegase a darse el caso que el demandante también enfrente un escenario de pérdidas (Kahneman, Knetsch, y Thaler, 1991, pp. 193-197) (inicia una acción sólo para restablecer su buen nombre o algún otro interés no evaluable económicamente), entonces, ello conducirá a procesos más largos, con mayores costos directos, lo que puede tener consecuencias distributivas. Esto último, se producirá si el demandante es un JO, quien muy probablemente no podrá replicar el esfuerzo de una contraparte que sea JR.

\section{Conclusiones}

La carencia de recursos económicos tiene repercusiones en múltiples ámbitos de la vida. Los litigios civiles constituyen un contexto donde esas carencias tienen consecuencias. Las reglas y principios que garantizan la igualdad de trato no son suficientes para hacer frente a tales problemáticas. La gratuidad también tiene sus limitaciones porque no fuerza necesariamente el inicio de las acciones procesales para quienes sienten que el litigio civil no es parte de sus necesidades acuciantes. Mecanismos más intervencionistas son necesarios para que la desigualdad económica reduzca sus implicancias distributivas en el proceso civil. Para que esos mecanismos estén debidamente focalizados en ciertos marcos de posibles conflictos donde esas problemáticas son más acuciantes. En este artículo, hemos desarrollado una idea transversal 
asociada a que uno de esos marcos corresponde al escenario donde un litigante recurrente se enfrenta a un litigante ocasional y este último es quien carece de recursos suficientes. Es posible identificar otros marcos y otros instrumentos diferentes a los aquí tratados, trabajos posteriores pueden ahondar en estas cuestiones y perfeccionar las ideas expuestas en este artículo.

\section{Bibliografía}

Aguirrezabal, M. (2010). "El control de la representatividad adecuada de las asociaciones de consumidores en el ejercicio de las acciones colectivas", en Revista de Derecho, vol. 22, N², 175-196. Chile, Universidad Austral.

Astorga, E., Carrillo, F., Folchi, M., García, M., Grez, B., McPhee, B., ...Stein, H. (2017). Evaluación de los conflictos socio-ambientales de proyectos de gran tamaño con foco en agua y energía para el periodo 1998 al 2015. Recuperado de https:// www.cnid.cl/wp-content/uploads/2017/04/Informe-final-CNID-Evaluacio\%CC\%81n-de-Conflictos-Socioambientales-1.pdf.

Atria, F. (2007). “La improbabilidad de la Jurisdicción”, en J. Couso y F. Atria (eds.), La Judicatura como organización (33-55), Chile. Instituto de Estudios Judiciales.

Babcock, L., Farber, H., Fobian, C., y Shafir, E. (1995). "Forming Beliefs about Adjudicated Outcomes: Perceptions of Risk and Reservation Values", en International Review of Law and Economics, vol. 15, N³, 289-303.

Barros, E. (2006). Tratado de responsabilidad extracontractual. Santiago, Editorial Jurídica.

Becker, G. (2009). Uncommon Sense. Chicago, The Univerity of Chicago Press.

Binmore, K. (2011). Teoría de Juegos. Una breve introducción. Madrid, Alianza Editorial.

Bordalí, A. (2016). "Nuevas herramientas probatorias en el proceso civil chileno. Análisis en un contexto de facilidad probatoria", en Revista de Derecho, año 23, N • 1,173-198. Chile, Universidad Católica del Norte.

Bordalí, A. (2013). "La igualdad de las partes en los procesos judiciales chilenos", en F. Muñoz (ed.), Igualdad, inclusión y derecho. Lo político, lo social y lo jurídico en clave igualitaria. Santiago, LOM Ediciones.

Bordalí, A. (2004). Tutela jurisdiccional del medio ambiente. Santiago, Editorial Fallos del Mes.

Bordalí, A., Cortez, G., y Palomo, D (2019). Proceso Civil. Los recursos y otros medios de impugnación. Santiago, Thomson Reuters.

Bravo, P. (2013). “Derrotabilidad de la carga de la prueba en la responsabilidad contractual: Hacia la facilidad probatoria en Chile", en Revista Chilena de Derecho Privado, No 21, 13-46. Chile, Universidad Diego Portales.

Cabrillo, F. (1989). Quiebra y liquidación de empresas. Madrid, Unión Editorial. 
Carrasco, J. (2006). "Algunas reflexiones acerca de la inadmisibilidad en el procedimiento establecido en la Ley 20.600 sobre tribunales ambientales", en Cuadernos de Extensión Jurídica, №28, 35-66. Chile, Universidad de Los Andes.

Carrasco, N. (2019). "Efectividad de las normas procesales civiles", en Revista de Derecho, vol. 52, 67-100. Chile, Pontificia Universidad Católica de Valparaíso.

Carrasco, N. (2018). "Consideraciones de eficiencia respecto del mecanismo de mediaciones colectivas de consumo", en R. Rivero y J.C. Marín (dircs.) y F. Ferrada (coord.), Reformas necesarias a la justicia chilena: VI Jornadas Nacionales de Derecho Procesal (315-341). Santiago, Librotecnia.

Carrasco, N. (2017). "El proceso civil como juego no repetitivo y como vía para interiorizar cargas informativas: Una mirada desde el análisis económico del derecho", en Revista Chilena de Derecho, vol. 44, N 1, 204-205. Chile, Pontificia Universidad Católica de Chile.

Carrasco, N., Núñez, R., y Coronado, M. (2018). “Compatibilidad entre debido proceso y eficiencia: su aplicación al régimen de apelación en el proceso civil chileno", en Revista de Derecho, vol. 31, N², 211-235. Chile, Universidad Austral.

Casarino, M. (2016). Manual de Derecho Procesal. Derecho Procesal Orgánico, Santiago, Editorial Jurídica de Chile, t. II.

Colegio De Abogados De Chile A.G. (2008). Opinión del Colegio de Abogados de Chile A.G, en materia de defensoría y asesoría legal a quienes no pueden procurársela por sus propios medios. Recuperado de https://archivo.colegioabogados.cl/admin/fckeditor/libreria/file/documentos\%20de\%20interes/oficio-37-08-Defensorias-Judiciales.pdf

Colombo, Juan (1968). "La jurisdicción en el derecho chileno", en Anales de la Facultad de Ciencias Jurídicas y Sociales, vol. 8. Chile, Universidad de Chile.

Cooter, R. y Rutherfor, D. (1989). "Economic Analysis of Legal Disputes and their resolution", en Journal of Economic Literature, vol. 27, N 3, 1067-1097. Estados Unidos, American Economic Association.

Cooter, R. y Ulen, T. (2008). Derecho y Economía. México DF, Fondo de Cultura Económica.

Damaska, M. (1986). The Faces of Justice and State Authority. New Haven, Yale University Press.

De Figuereido, J. y De Figuereido, R. (2000). "The Allocation of Resources by Interest Group: Lobbying, Litigation, and Administrative Regulation", en Harvard Law and Economics Discussion Paper N ${ }^{\circ}$ 364. Recuperado de http://www.law.harvard. edu/programs/olin center/papers//pdf/364.pdf

Díez-Picazo, I. Borrajo, I. y Fernández, G. (1995). El derecho a la tutela judicial y el recurso de amparo. Una reflexión sobre la jurisprudencia constitucional. Madrid, Civitas. 
Diez, J. L. (2016). “La acción de daño contingente del artículo 2333 del Código Civil chileno: sus elementos y ámbito de aplicación", en Revista de Derecho de la Pontificia Universidad Católica de Valparaíso, vol. 46, 133-153. Chile, Pontificia Universidad Católica de Valparaíso.

Donário, A. (2008). ¿Aumento de las sanciones o de las probabilidades de aplicación de la ley?, 2008. Recuperado de http://www.ief.es/documentos/investigacion/ seminarios/economia publica/2008 24Enero.pdf.

Donohue, J. (1991). "The effects of fee shifting on the settlement rate: Theorical Observations on Cost, Conflicts, and Contingent Fees", en Law and Contemporary Problems, vol. 54, N³, 195-222. Estados Unidos, Duke University School of Law.

Donohue, J. (1990-1991). "Opting for the British Rule, Or If Posne and Shavell Can't Remember the Coase Theorem, Who Will?", en Harvad Law Review, vol. 104, 1093-1119. Estados Unidos, Harvard University.

Galanter, M. (1974). “Why the 'Haves` Come Aout Ahead: Speculations on the Limits of Legal Change", en Law \& Society Review, vol. 9, N¹, 95-160. Estados Unidos, Duke University School of Law.

Gamonal, S. (2013). "El principio de protección del trabajador en la constitución chilena", en Estudios Constitucionales, vol. 11, N 1, 424-458. Chile, Universidad de Talca.

Giannini, L. (2019). “Revisitando la doctrina de la carga dinámica de la prueba, aportes para esclarecer sus principales problemas conceptuales", en J. Nieva. J. Ferrer. y L. Gianini (auts.), Contra la carga de la prueba (89-114). Madrid, Marcial Pons.

Gould, J. (1973). "The Economics of Legal Conflict", en The Journal of Legal Studies, vol. 2, $N^{\circ} 2$ 2, 279-300. Estados Unidos, The University of Chicago Law School.

González, A. (2007). "La delación compensada o Aministía en la lucha anti-carteles", en Trabajos de Investigación en Políticas Públicas, N ${ }^{\circ} 2,1-10$. Chile, Universidad de Chile.

González, A. y Micco, A. (2014). "Private versus public enforcement: Evidence from Chile", en Journal of Competition Law anc Economics, vol. 4, N 10, 691-709. Inglaterra, Oxford University Press.

Harvey, D. y Reed, M. (1996). "The Culture of Poverty: An Ideological Analysis", en Sociological Perspectives, vol. 39, N 4, 465-495. Estados Unidos, Pacific Sociological Association.

Herrera, R. (1991). "La inversión de la carga de la prueba: ¿Manifestación del "In Dubio Pro Operario"?", en Thémis vol. 18, 41-45. Perú, Pontificia Universidad Católica del Perú.

Howard, J. W. (1969). "Adjudication Considered as a Process of Conflict Resolution: A variation on Separation of Powers", en Journal of Public Law, vol. 18, 339-368. Estados Unidos, Emory University Law School. 
Howe, L. (1998). "Where is the Culture in the "Culture of Poverty"?, en The Cambridge Journal of Anthropology, vol. 20, N 1, 66-91. Inglaterra, Cambridge University.

Huerta, J. M. (2012). Reglas de costas y sanciones pecuniarias: un análisis económico para la reforma procesal civil en Chilena. Recuperado de https://sistemasjudiciales.org/wp-content/uploads/2018/08/notasgenerales jhuerta.pdf.

Hunter, I. (2010). "Iura novit curia en la jurisprudencia civil chilena", en Revista de Derecho, vol. 23, N² 2,197-221. Chile, Universidad Austral.

Kahneman, D. (2017). Pensar rápido, pensar despacio. Bogotá, Random House Mondadori.

Kahneman, D. Knetsch, J. y Thaler, R. (1991). "The Endowment Effect, Loss Aversion, and the Status Quo Bias", en The Journal of Economic Perspectives, vol. 5, N ${ }^{\circ} 1$, 193-206. Estados Unidos, American Economic Association.

Kaplow, L. y Shavell, S. (2002). Fairness versus Welfare. Massachusetts, Harvard University Press.

Katz, A (1990). "The effect of frivolous lawsuits on the settlement of litigation", en International Review of Law and Economics, vol. 10. 3-27. Holanda, Elsevier.

Lagos, M. Poggi, H. y Mellado, C. (2011). “Conceptos básicos sobre el estudio de paternidad", en Revista Médica de Chile, vol. 139, N 39, 542-547. Chile, Sociedad Médica de Santiago.

Landes, W. y Posner, R. (1979). "Adjudication as a Private Good", en The Journal Legal Studies, vol. 8, 235-284. Estados Unidos, The University of Chicago Law School.

Lewis, 0. (1966). “The Culture of Poverty”, en Scientific American, vol. 215. N 4, 19-25. Estados Unidos, Nature Publishing Group.

Menell, P. (1983). "A Note on Private versus Social Incentives to Sue in a Costly Legal System", en The Journal of Legal Studies, vol. 12, pp. 41-52. Estados Unidos, The University of Chicago Law School.

Mery, R. (2006). "Una aproximación Teórica y Empírica a la Litigación Civil en Chile". Recuperado de http://works.bepress.com/rafael mery nieto/1.

Montero, J. Ortells, M. y Gómez, J. (1994). Derecho Jurisdiccional. Barcelona, Bosch.

Mosier, M. y Soble, R. (1973). "Modern Legislation Metropolitan Court, Miniscule Results: A Study of Detroit's Landlord-Tenant Court", en University of Michigan Journal of Law Reform, vol. 7, 8-70. Estados Unidos, University of Michigan.

Muñoz, F. (2013). Igualdad, inclusión y derecho. Lo político, lo social y lo jurídico en clave igualitaria. Santiago, LOM Ediciones.

Munita, E. (2014). "El principio protector y la regla del in dubio pro operario como criterio de interpretación de la norma laboral", en Revista Chilena de Derecho del Trabajo y de la Seguridad Social, vol. 5, N 19, 85-94. Chile, Universidad de Chile. 
Pardow, D. (2015). “El desempeño en juicio de la FNE: ¿Es realmente un mejor litigante que los demandantes privados?, en Revista de Derecho, año 22, N², 419-451. Chile, Universidad Católica del Norte.

Pastor, S. (2003). Cuadernos de Derecho Judicial: El coste de la justicia. Madrid, Consejo General del Poder Judicial.

Posner, R. (1998-1999). "An Economic Approach to the Law of Evidence", en Stanford Law Review, vol. 51, No 1, 1477-1546. Estados Unidos, University of Stanford.

Ross, L. (1970). Settled Out of Court: The social Process of Insurance Claims Adjustment. Chicago, Aldine.

Ross, S. (1973). "The Economic Theory of Agency. The Principal's Problem", en American Economic Review, vol. 63, 134-139. Estados Unidos, American Economic Association.

Rowntree, B. S. (2000). Poverty: A Study of Town Life. Bristol, Policy Press.

Ruay, Francisco, "Análisis crítico de las potestades atípicas del juez laboral ante el principio de juridicidad", Revista Chilena de Derecho del Trabajo y de la Seguridad Social, vol. 5, núm. 9, 2014, pp. 83-105.

Ruay, F. (2015). “La función cautelar del juez en el proceso laboral ¿Consagración de una potestad cautelar genérica?, en lus et Praxis, vol. 21, N² 2, pp. 441-480. Chile, Universidad de Talca.

Ruiz Tagle, P. (1990). "Análisis comparado de la función judicial", Estudios Públicos, vol. 39, 131-162. Chile, Centro Estudios Públicos.

Santos, H. (2000). Teoría General del Proceso, México DF, McGraw-Hill.

Schiele, C. y Tocornal, J. (2010). "Artículo 2329 del Código Civil. La interpretación de presunción por hechos propios existe en la Jurisprudencia”, en Revista Chilena del Derecho, vol. 37, 123-139. Chile, Pontificia Universidad Católica de Chile.

Scitovsky, T. (1986). Frustraciones de la riqueza. La satisfacción humana y la insatisfacción del consumidor. Ciudad de México, Fondo de Cultura Económica.

Sen, A. (2013). La idea de la justicia. Ciudad de México, Taurus.

Stürner, R. (2007). “Derecho procesal y culturas jurídicas", en Revista lus et Praxis, vol. 13, $N^{\circ} 1,435-462$. Chile, Universidad de Talca.

Rachlinski, J. (1996). "Gains, Losses, and the Psychology of Litigation", en Southern California Law Review, vol. 70, 113-185. Estados Unidos, USC Gould School of Law.

Tversky, A. y Kahneman, D. (1986). "Rational Choice and the Framing od Decisions", en The Journal of Business, vol. 59, $N^{\circ} 4,251-278$. Estados Unidos, The University of Chicago Press. 
Ugarte, J. L. (2009). "Tutela laboral de derechos fundamentales y carga de prueba", en Revista de Derecho, vol. 33, 215-228. Chile, Pontificia Universidad Católica de Valparaíso.

Verdugo, S. y García, J. F. (2013). Activismo judicial en Chile ¿Hacia el gobierno de los jueces? Santiago, Ediciones L\&D.

Zanzucchi, M. (1947). Diritto Processuale Civile. Varese, Giuffrè-editore. 